Horst Paul Kuhley, Elisabeth Gessner (Hrsg.)

\title{
Mehrsprachigkeit als Chance
}

Tagungsband zum internationalen Workshop

über Migration und Multilingualität

in Schule und Hochschule

14. und 15. Mai 2009

an der Universität Kassel

Veranstalter: Projekt „Lesekompetenz“

im Zentrum für Lehrerbildung 
Elisabeth Gessner ist Lehrerin für die Sekundarstufen I und II, Fächer Deutsch und Politik. Von 1999 bis 2004 in der Lehrerfortbildung tätig, 2004 bis 2006 Mitarbeit in einem Forschungsprojekt an der Universität Kassel, seit 2005 Pädagogische Mitarbeiterin in der Lehrerbildung. Schwerpunkte: PISA, Lesekompetenz, Diagnostik, Deutschdidaktik und fächerübergreifendes Lernen.

Horst Paul Kuhley ist Lehrer für die Sekundarstufen I und II, Fächer Englisch und Politik. Von 1996 bis 2004 in der Lehrerfortbildung des Landes Hessen, tätig seit 2004 an einem Gymnasium, seit 2005 außerdem Pädagogischer Mitarbeiter an der Universität Kassel. Schwerpunkte: Schulentwicklung, interkulturelles Lernen, Fremdsprachen, die Europäische Dimension, Schreiben in der Sekundarstufe.

Projekt Lesekompetenz

http://www.uni-kassel.de/fb1/lesenundschreiben/

Bibliografische Information der Deutschen Nationalbibliothek

Die Deutsche Nationalbibliothek verzeichnet diese Publikation in der Deutschen Nationalbibliografie; detaillierte bibliografische Daten sind im Internet über http://dnb.d-nb.de abrufbar

Horst Paul Kuhley, Elisabeth Gessner (Hrsg.)

Mehrsprachigkeit als Chance

Kassel 2009

2009, kassel university press GmbH, Kassel

www.upress.uni-kassel.de

ISBN 978-3-89958-490-5

Redaktion und Layout: Sebastian und Annerose Ritter, Kassel

Umschlaggestaltung: Daniel Fitzner, Kassel

Druck: Unidruckerei der Universität Kassel

Printed in Germany 


\section{INHALTSVERZEICHNIS}

Vorwort

\section{Klaus Rummler (Kassel)}

Vom Bemühen um Internationalität

Martha Orban-Kerst (Eupen, Belgien)

Sandra Kringels (Eupen, Belgien)

Mehrsprachigkeit als pädagogische Selbst-

verständlichkeit am Beispiel der Deutsch-

sprachigen Gemeinschaft in Belgien

Monika Witt (Neisse/Nysa, Polen)

Alina Kowalczyk-Dittmann (Neisse/Nysa, Polen)

Situation der deutschen Sprache im Oppelner Land

Adam Morcinek (Neisse/Nysa, Polen)

Projekt: Literarische Spaziergänge durch Neisse

Monika Moschek (Neisse/Nysa, Polen)

Deutschunterricht im Kindergarten

Ines Tobis (Kassel)

Studieren mit Mehrwert 36

\section{Michael Koenig (Kassel)}

Das Fachgebiet Deutsch als

Fremdsprache / Zweitsprache an der

Universität Kassel 


\section{Harun Osmani (Vantaa, Finnland)}

Mehrsprachigkeit als Chance ............................................... 61

\section{Kristiina Ikonen}

(Finnisches Zentralamt f. Unterrichtswesen)

Schüler mit Migrationshintergrund

in finnischen Schulen

Petra Linderoos (Jyväskylä, Finnland)

Das Finnische Schul- und Ausbildungssystem 74

Elisabeth Gessner (Kassel)

Horst Paul Kuhley (Kassel)

Schule - Sprache - Migration ................................................. 85 


\section{VORWORT}

\section{Mehrsprachigkeit als Chance - Ein Beitrag zur Internationali- sierung der Lehrerbildung}

Diese Veröffentlichung dokumentiert einen Zwischenschritt auf dem Weg zu einer Internationalisierung des gesellschafts- und erziehungswissenschaftlichen Kernstudiums in der Lehrerbildung an der Universität Kassel. In ihr finden sich Beiträge und Materialien, die Gegenstand eines Workshops zum Thema „Mehrsprachigkeit als Chance" waren, der am 14. und 15. Mai 2009 stattfand. Der Workshop stellte ein Forum dar, in welchem Kolleginnen und Kollegen aus Finnland, Belgien, Polen und Deutschland die Ansätze ihrer Länder zum Umgang mit Mehrsprachigkeit präsentieren konnten. Eine Besonderheit war dabei die Teilnahme von Studierenden, nicht nur als Zuhörer, sondern auch als Präsentierende.

Die Veranstaltung ordnet sich in unsere Bemühungen ein, dem Studium am Fachbereich Erziehungswissenschaft/Humanwissenschaften eine Europäische Dimension zu verleihen. Studierende, auch wenn sie keine moderne Fremdsprache als Fach vertreten, sollen auf eine Situation vorbereitet werden, in der sie mit Schülerinnen und Schülern diverser Sprachen und Kulturen inkludierend umgehen können. Die dazu nötigen Kompetenzen können unserer Ansicht nach nur am leichtesten entwickelt werden, wenn bereits in der ersten Ausbildungsphase themenbezogene interkulturelle Begegnungen ermöglicht werden.

Die Sprachbarriere stellt nicht nur für Schülerinnen und Schüler mit Migrationshintergrund in unseren Schulen einen Hinderungsgrund zum Schulerfolg dar, sie stellt auch für Studierende - wenn sie nicht eine moderne Fremdsprache gewählt haben - vor Schwierigkeiten, wenn sie eine Auslandserfahrung machen wollen. Außerdem behindern einige Förderungsbedingungen für internationale Austausch- 
programme mit ihren Bestimmungen das interkulturelle Differenzerlebnis, das durch das Studieren im Ausland ermöglicht wird: Einmal als Fremder im Ausland allein zu sein. Als erste Konsequenz aus dieser Erkenntnis haben wir den Workshop „Mehrsprachigkeit“ auch für Studierende geöffnet. Die angestrebte zweite Konsequenz ist es aber, Studierenden im erziehungswissenschaftlichen Kernstudium an der Universität Kassel eine wenig aufwendige Möglichkeit zur Auslandserfahrung zu geben. Der Workshop „Mehrsprachigkeit als Chance" gab unseren Studierenden und uns die Gelegenheit, Partnerregionen im Ausland kennen zu lernen, in denen kürzere und längere Aufenthalte zum Studium des Umgangs mit Mehrsprachigkeit angestrebt werden.

Ziel der weiterführenden Arbeit nach dem Workshop ist die Festigung der Auslandsbeziehungen, um für die Studierenden aller Fächer der Lehrämter ein Netzwerk für Praktika und andere Auslandsaufenthalte zu schaffen. Ein erster Schritt in Richtung auf ein solches Netzwerk ist der geplante Hospitationsbesuch einer Delegation von Dozenten, Lehrern und Studierenden aus der Region Kassel in Schulen der Region Neisse/Nysa in Polen im Sommersemester 2010. Deshalb danken wir an dieser Stelle Herrn Professor Dr. Wollring für seinen Beitrag zur historischen Perspektive des deutschpolnischen Austauschs bei der Begrüßung der Workshopteilnehmer.

Wir bedanken uns beim Fachbereich Erziehungswissenschaft/ Humanwissenschaften, beim Zentrum für Lehrerbildung, beim Akademischen Auslandsamt und bei der Universitätsbibliothek der Universität Kassel für die Unterstützung unseres Workshops und die Förderung dieser Veröffentlichung.

Kassel, im Oktober 2009

Horst Paul Kuhley und Elisabeth Gessner 


\section{KLAus RummLeR}

Vom Bemühen um Internationalität

Klaus Rummler, Fachgebiet Medienpädagogik an der Universität Kassel

Klaus Rummler befasst sich in seiner Präsentation "Vom Bemühen um Internationalität" mit der Schaffung der nötigen Rahmenbedingungen für ein erfolgreiches Studium im Ausland.

In his presentation ,Vom Bemühen um Internationalität“ Klaus Rummler deals with the creation of necessary framework conditions for studying abroad successfully.

\section{Vom Bemühen um Internationalität}

Studieren im Ausland und die Schaffung entsprechender Rahmenbedingungen

Klaus Rummler M.A. ECTS Erasmus Departmental Coordinator FB1, Universität Kassel

Mehrsprachigkeit als Chance. Internationaler Workshop zu Migration und Multilingualität in Schule und Hochschule

15. Mai 2009 


\section{Punkte des Bologna Prozesses}

1. drei große Zyklen

- BA-Studium - MA-Studium - PhD.

- internationale Vergleichbarkeit

- Flexibilität bei Einstieg ins Studium/Weiterbildung

\section{Punkte des Bologna Prozesses}

2. Anrechnung von Studienleistungen (ECTS)

- Vereinfachter Hochschulwechsel, Mobilität

- Vergleichbarkeit der Leistungen 


\section{Punkte des Bologna Prozesses}

3. Diploma Supplement

- allgemeine, internationale Anerkennung

- Verständlichung der Abschlüsse gegenüber Arbeitgebern

\section{Punkte des Bologna Prozesses}

4. Förderung von Mobilität

- Mobilität Lehrender

- Mobilität Studierender

- Mobilität des Verwaltungspersonals 


\section{Punkte des Bologna Prozesses}

5. Förderung der europäischen Zusammenarbeit bei der Qualitätssicherung

- Evaluierung bestehend aus interner Bewertung, externer Beurteilung, Beteiligung der Studierenden, Veröffentlichung der Ergebnisse.

- Akkreditierung, Zertifizierung

- Internationale Beteiligung, Vernetzung.

- Auftrag an die ENQA: Methode des peer-reviews entwickeln (TEEP I, TEEP II)

\section{Punkte des Bologna Prozesses}

Zusammenschluss der 45 Bologna-Staaten zur EHEA bis 2010 (European Higher Education Area)

- Curriculum-Entwicklung

- Zusammenarbeit zwischen Hochschulen

- Mobilitätsprojekte

- integrierte Studien-, Ausbildungs- und Forschungsprogramme. 


\title{
Rahmen für internationales Studieren
}

\author{
Internationale Konsortien als Rahmen für
} internationales Studieren und internationale

Forschung

Als Modell und Rahmenprogramm:

Erasmus Mundus I und II

\section{Das (Studien-)Konsortium}

- Dem Programm und dem Konsortium einen Namen geben

- Eine Website als Plattform

- Eine klare regierungsfähige Struktur

- Vertragliche Verbindung der Partner

- Regelmäßige gemeinsame Treffen

- Regelmäßige Berichte innerhalb der Partner 


\section{Konkrete Herausforderungen}

„We don't have problems - we have challenges“

Common understanding

Common curriculum

Gemeinsame administrative Strukturen

\section{Qualitätssicherung für Kundenzufriedenheit}

- Studierende als Kunden

- Zusammen mit dem Arbeitsmarkt und den akademischen Standards Qualität formulieren

- Selbstevaluierung 


\section{Permanente Evaluierungen}

1) Evaluation der Einbindung / Einordnung / Kohärenz der Lehrveranstaltungen

2) Evaluation der lokalen Lehrveranstaltungen

3) Evaluation der Infrastruktur

4) Evaluation des Workload

\section{1) Evaluation der Einbindung der Lehrveranstaltungen}

- Ständige gegenseitige Information und Abstimmung über Studieninhalte

- Wie sehen die Lehrveranstaltungen an den Partneruniversitäten aus?

- Gegenseitige Hospitationen in Lehrveranstaltungen 


\section{2) Evaluation der lokalen Lehrveranstaltungen}

Standardisierter Fragebogen in Bezug auf

- denInhalt der Lehrveranstaltung

- den Dozent

- allgemeine Rahmenbedingungen

- Allgemein auf die Lehrveranstaltung

Die Fragen decken folgende Dimensionen ab:

- Didaktik

- Lernumgebung

- Einsatz von Medien

- Lernkomplexität / Lernaufwand

\section{3) Evaluation der Infrastruktur}

- Unterkunft

- Forschungsprojekte

- Technische Ausstattung

- Bibliothek, Rechenzentrum, etc 


\section{3) Evaluation des Workload}

Workload $=$ Selbststudium + Kontaktstunden

2 Selbststudium : 1 Kontaktstunden

1 Semester $=900$ Stunden $($ à $60 \mathrm{Min})=30 \mathrm{ECTS}$

30 ECTS $=$

600 Std. Selbststudium +300 Std. Kontaktstunden

\section{Dokumente mit Relevanz zu QS}

- Gemeinsames administratives Handbuch

- Student and Course Handbook

- Kalender

- Studienverlaufsplan

- Prüfungsordnungen

- ECTS-Paket: Bewerbungsformulare, Transcript of Records, Studienvertrag 


\title{
Martha Orban-Kerst SANDRA KRINGELS
}

\author{
Mehrsprachigkeit als Chance, \\ als pädagogische Selbstverständlichkeit \\ am Beispiel der Deutschen \\ Gemeinschaft Belgiens
}

Martha Orban-Kerst, Autonome Hochschule in der Deutschsprachigen Gemeinschaft, Eupen, Belgien

Sandra Kringels, Autonome Hochschule in der Deutsch-sprachigen Gemeinschaft, Eupen, Belgien

In der Präsentation „Mehrsprachigkeit als pädagogische Selbstverständlichkeit am Beispiel der Deutschsprachigen Gemeinschaft Belgiens", referieren Martha Orban-Kerst und Sandra Kringels über die Hintergründe, Konzepte und die Bildungsmöglichkeiten innerhalb der Deutschsprachigen Gemeinschaft in Ostbelgien. Der Schwerpunkt des Vortrags liegt beim Aufbau des Bildungssystems unter Berücksichtigung des Zweitsprachenunterrichtes.

In the presentation "Mehrsprachigkeit als pädagogische Selbstverständlichkeit am Beispiel der Deutschsprachigen Gemeinschaft Belgiens“", Martha Orban-Kerst and Sandra Kringels are presenting the background, different concepts and manners of education within the German-speaking community in Eastern Belgium. The focus lies on the structure of the educational system considering the teaching of a second language. 


\title{
Mehrsprachigkeit
} als pädagogische Selbstverständlichkeit am Beispiel der Deutschsprachigen Gemeinschaft Belgiens

\author{
Martha Orban-Kerst
}

Sandra Kringels

Kassel, 14.-15.Mai 2009

\section{Belgien und Ostbelgien 2. Das Bildungswesen in der Deutschsprachigen Gemeinschaft Belgiens}




\section{Die Deutschsprachige Gemeinschaft Belgiens}

Die Deutschsprachige Gemeinschaft in Belgien, gelegen im östlichen Teil des Landes an den Grenzen zum Großherzogtum Luxemburg im Süden, zur Bundesrepublik Deutschland im Osten, zum Königreich der Niederlande im Norden und zur Französischsprachigen Gemeinschaft Belgiens im Westen, ist trotz seiner geringen Ausdehnung (etwa $870 \mathrm{~km}^{2}$ ) und Bevölkerungszahl (etwa 75.000 Einwohner) in der Sprach- und Minderheitenforschung ein äußerst interessantes Betätigungsfeld: Sowohl die sprachliche als auch die geschichtliche Entwicklung zeugen von einer in einem solch kleinen Gebiet unerwarteten Vielfalt.

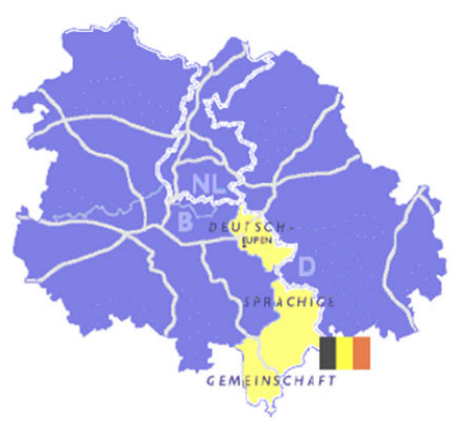

\section{Kartografische Übersicht}

Die Deutschsprachige Gemeinschaft ist Grenzgebiet: 7 der neun Gemeinden grenzen an die BRD und 7 Gemeinden grenzen an die Französische Gemeinschaft Belgiens.

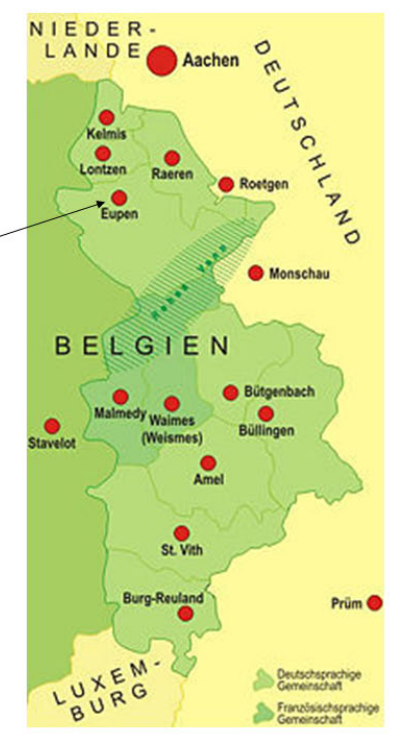




\section{Eckpfeiler}

\subsubsection{Die Schulpflicht}

- Gesetz vom 19. Mai 1914: Schulpflicht für alle Kinder von 6 bis12 Jahren

- derzeit gültiges Gesetz vom 29. Juni 1983: Ende der Pflichtschulzeit auf 18 Jahre (12 Schuljahre)

Ziel: $\Longrightarrow$ bessere Qualifizierung

$\Longrightarrow$ leichterer Einstieg ins Berufsleben

- Ab Erreichen des fünfzehnten Lebensjahres: Teilzeitschulpflicht

- weiter ganztägig eine Sekundarschule besuchen

- ein Zentrum für Teilzeitunterricht besuchen

- ein von den Behörden anerkanntes Ausbildungsprogramm (zum

Beispiel eine mittelständische Ausbildung) absolvieren

- Während der Schulpflichtzeit: Zugang zum Unterricht ist unentgeltlich

\section{Die Schulnetze}

\begin{tabular}{|l|c|c|c|c|c|}
\hline & $\begin{array}{l}\text { Primar- } \\
\text { schulen }\end{array}$ & $\begin{array}{l}\text { Sekundar- } \\
\text { schulen }\end{array}$ & $\begin{array}{c}\text { Sonder- } \\
\text { schulen }\end{array}$ & Hochschule & $\begin{array}{l}\text { Institute für } \\
\text { Weiterbildung }\end{array}$ \\
\hline $\begin{array}{l}\text { Freies } \\
\text { subventioniertes } \\
\text { Unterrichtswesen }\end{array}$ & $\mathrm{X}$ & $\mathrm{X}$ & $\mathrm{X}$ & - & $\mathrm{X}$ \\
\hline $\begin{array}{l}\text { Offizielles } \\
\text { subventioniertes } \\
\text { Unterrichtswesen }\end{array}$ & $\mathrm{X}$ & $\mathrm{X}$ & - & - & $\mathrm{X}$ \\
\hline $\begin{array}{l}\text { Gemeinschafts- } \\
\text { unterrichtswesen }\end{array}$ & $\mathrm{X}$ & $\mathrm{X}$ & $\mathrm{X}$ & - & $\mathrm{X}$ \\
\hline
\end{tabular}




\subsection{Die Verteilung der 13.693 Schüler im Schuljahr 2008-2009 auf die 3 Unterrichtsnetze in der DG}

Offizielles

subventioniertes

Unterrichtswesen

$\square$ Freies subventioniertes

Unterrichtswesen

$\square$ Gemeinschaftsunterrichtswesen

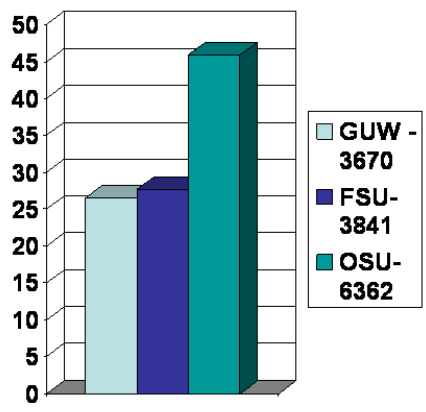

4. Schülerzahlenentwicklung seit dem Schuljahr 1988-1989 bis 2008-2009

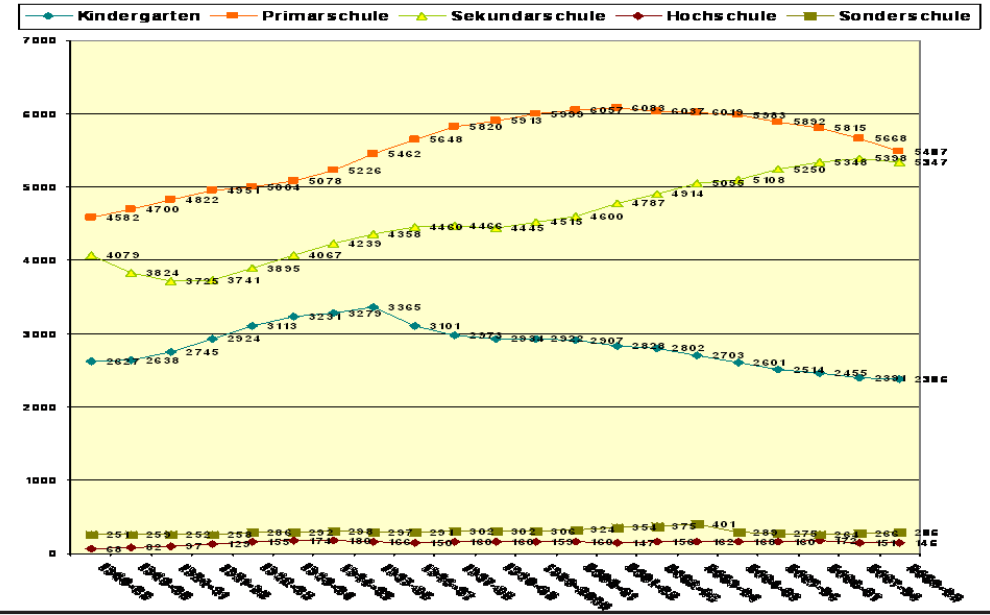




\subsection{Schülerverteilung in der DG auf die verschiedenen} Schulebenen im Schuljahr 2008-2009

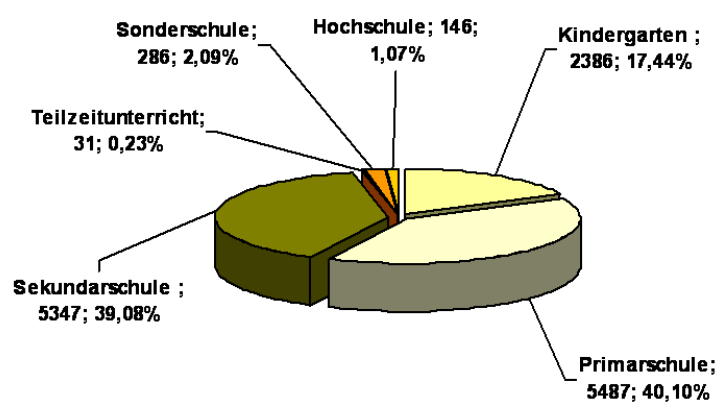

\subsection{Die Schulpopulation}

- $21,48 \%$ der Schüler

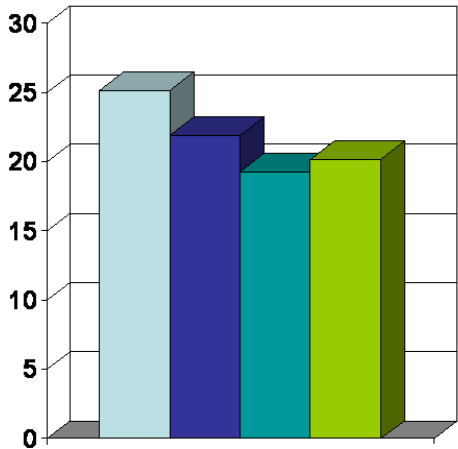

besitzen eine ausländische Nationalität

\section{$\square$ Kindergarten}

- Primatschule $\square$ Sekundarschule $\square$ Hochschule 


\section{1,48\% ausländischer Herkunft}

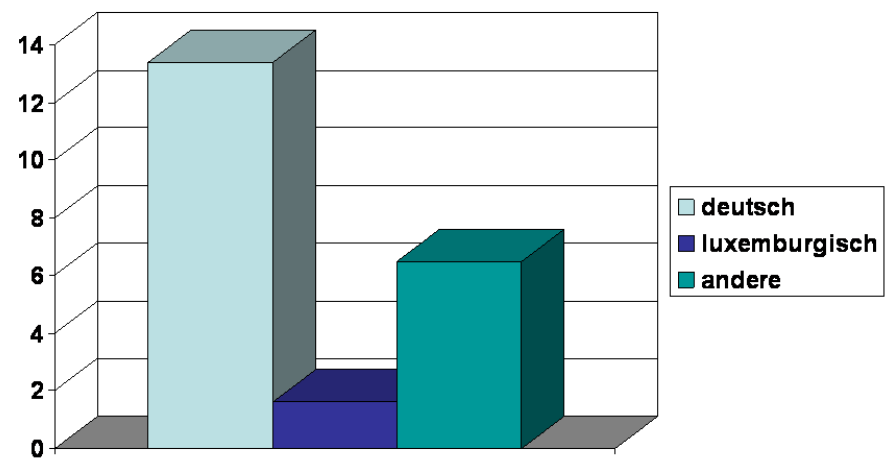

4.3. Wohnort der Primar- und Sekundarschüler in der DG

- $88,05 \%$ wohnen in der DG

- $11,95 \%$ wohnen außerhalb der DG

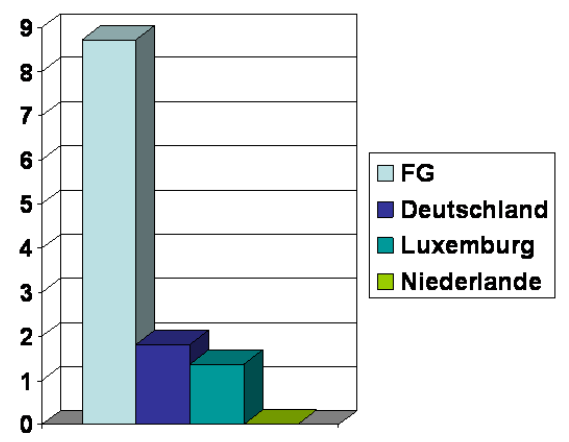




\section{Gesellschafts-, Erziehungs- und Schulprojekt}

- Das Dekret vom 31.8.1998

- Prinzipien der Bildungs- und Erziehungsarbeit:

- Persönlichkeitsentwicklung und Selbstverwirklichung des Schülers

- Chancengleichheit und Gleichberechtigung der Geschlechter

- Toleranz und Solidarität, Achtung vor dem Mitmenschen

- Verantwortlicher Umgang mit der Umwelt und der Natur

- Demokratisches Grundverhalten, Vermittlung von Kenntnissen, Fähigkeiten und Fertigkeiten sowie Weltoffenheit

- Mehrsprachigkeit und Förderung des europäischen Gedankens

\section{Struktur des Unterrichtswesens in der Deutschsprachigen Gemeinschaft}
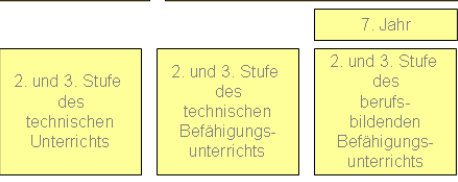


\section{Die Schulebenen in der DG}

\section{Der Kindergarten Unterrichtswesen}

- fester Bestandteil des Unterrichtswesens in Belgien

- Uneingeschränktes Recht auf einen kostenlosen Kindergartenplatz ab dem Alter von drei Jahren.

- Keine Schulpflicht $\longrightarrow 98 \%$ der dreijährigen Kinder (regelmäßig)

- Sprachförderung, die Sozialisierung und die Persönlichkeitsentfaltung des Kindes

- Ausgewogene geistige, körperliche und psychomotorische Entwicklung sowie Förderung der Kreativität

- Anregung des Reifeprozesses, Entwicklung der Selbstständigkeit und des Verantwortungsbewusstseins

- Erleichterung grundlegender Lernprozesse und Fördr

- Aktivitätenplan (Dekret vom 29. April 1999):

1. mutter- und fremdsprachliche Aktivitäten

2. psychomotorische Aktivitäten

3. kreative Aktivitäten

4. mathematische und naturwissenschaftliche Aktivitäten

5. Aktivitäten zum Erlernen lebenspraktischer Fähigkeiten und sozialen Verhaltens

\subsection{Die Primarschule}

- Lehrangebot, Kernkompetenzen und Rahmenpläne (seit September 2008)

- Sprache: Schulträger legt zeitlichen Umfang der fremdsprachlichen Aktivitäten im Rahmen fest.

- $\quad$ verpflichtende Fächer oder Fachbereiche (Dekret vom 29. April 1999):

- Muttersprache

- erste Fremdsprache

- Mathematik

- Naturwissenschaften

- Kunst und Handwerk

- Leibeserziehung

- Weltorientierung

- Religion beziehungsweise nichtkonfessionelle Sittenlehre 


\subsection{Die Sekundarschule}

- Lehrangebot, Kernkompetenzen und Rahmenpläne (seit September 2008)

- Rahmenpläne

- Deutsch als Unterrichtsprache

- Französisch als erste Fremdsprache

- Mathematik

- Geschichte - Geografie

- Naturwissenschaften - Technik

- Musik - Kunst

- Sport

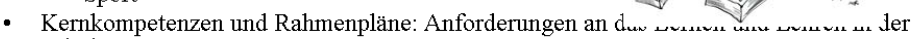
Schule

- welche Bildungsziele bis zu einer bestimmten Jahrgangsstufe

- Sicherung der schulischen Bildungsqualität,

- Vergleichbarkeit der Schulabschlüsse

- Bildungsgerechtigkeit

- Kompetenzmodell: fachbezogene und überfachliche Kompetenzen

- Kompetenzorientiert unterrichten: Schüler im Zentrum des Unterrichtsgeschehens

- zeitlicher Umfang des Französischunterrichts:

- allgemeinbildender Unterricht: vier Unterrichtsstunden pro Woche

- technischer und berufsbildender Unterricht: zwei Unterrichtsstunden pro Woche

\section{Zweitsprachenunterricht}




\section{Dekret vom 19. April 2004 über die Vermittlung und den Gebrauch der Sprachen im Unterrichtswesen}

- Pädagogisch-didaktische Methodenfragen unterliegen der Freiheit des Schulträgers.

- Einige wichtige Elemente (z.B. Rahmenpläne) werden durch andere Gesetzestexte geregelt.

- Andere Maßnahmen wiederum (z.B. Bekämpfung des Lehrermangels) müssen getrennt und parallel in Angriff genommen werden.

- GESAMTPAKET

\section{Starke Förderung der ersten Fremdsprache}

-Unterrichtssprache $\longrightarrow$ Sprache des jeweiligen Gebietes: Deutsch außer Grundschulen: Schutz der französischen Minderheit in der DG

- In der DG 1. Fremdsprache (per Gesetz):

- Französisch

- Deutsch in französischsprachigen Primarschulen der DG

\begin{tabular}{|c|c|c|c|}
\hline & 1.+2. Jahr & 3.+ 4. Jahr & 5.+6.Jahr \\
\hline Kindergarten & 50-200 Minuten Woche & 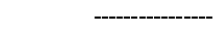 & 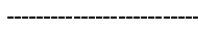 \\
\hline Primarschule & $\begin{array}{l}\text { Frz.2-3 } \\
\text { Stunden } N \text { Noche }\end{array}$ & $\begin{array}{l}\text { Frz.3-4 } \\
\text { Stunden } N \text { Noche }\end{array}$ & $\begin{array}{l}\text { Frz. } 5 \\
\text { Stunden } N \text { Noche }\end{array}$ \\
\hline Sekundarschule & Frz. 4 Stunden Woche & $\begin{array}{l}\text { Frz. } 2 \text { oder } 4 \\
\text { Stunden } N \text { Noche }\end{array}$ & $\begin{array}{l}\text { Frz. } 2,4 \text { oder } 6 \\
\text { Stunden } N \text { Woche }\end{array}$ \\
\hline
\end{tabular}

1. wechselvolle Geschichte des Gebietes und deren Auswirkung auf den Sprachgebrauch

2. großes wirtschaftliches Interesse für Mehrsprachigkeit in einem Grenzgebiet zwischen germanischer und romanischer Kultur 


\section{Grundschule: Fremdsprachenunterricht}

- In den Grundschulen der DG: Französisch als erste und einzige Fremdsprache

- In den französischsprachigen Grundschulen und Grundschulabteilungen: Deutsch als erste Fremdsprache

- Abschlusszeugnis: Unterrichtssprache

- Studie des Netzwerks Eurydice (November 2008): Schüler in der EU erlernen immer früher eine Fremdsprache.

- Mit 3 Jahren: DG und autonome Gemeinschaften Spaniens

- europäische Grundschulen:

$10 \%$ der Unterrichtszeit

- In den Schuljahren 2008-2009 bis einschließlich 2010-2011: Fremdsprachenunterricht von Kindergärtnern bzw. Primarschullehrern erteilt, die diese Bedingungen nicht erfüllen: Übergangsphase:

- DELF-Sprachenprüfung für das Niveau B2 mindestens $60 \%$ in jedem der vier Kompetenzbereiche (Lese- und Hörverständnis, schriftlicher und mündlicher Ausdruck)

- Regularisierungsverfahren beim Ministerium der DG (Prüfung Niveau B2)

\section{Einsatz von Native Speakern in der Grundschule}

- Abkommen zwischen der Französischen und der Deutschsprachigen Gemeinschaft

- Austauschprinzip "eins zu eins"

- Der Austausch ändert nichts am pädagogischen Studiengang der Schüler

- pädagogisches Programm: Ziele des Austauschs, Stundenaufteilung und Stundenplan

- Fremdsprachenunterricht und/oder andere in der Fremdsprache durchgeführte Aktivitäten Rahmenplänen der Deutschsprachigen Gemeinschaft und "socles de compétences" der Französischen 


\section{Sprachen in der Sekundarschule}

- Unterricht der ersten Fremdsprache (allgemeinbildender Unterricht $)=$ Wochenstundenzahl des Muttersprachenunterrichts

- Französischunterricht

- Sachunterricht in französischer Sprache

- bilingualer Sachfachunterricht

\section{Rahmenplan: Fach: Französisch als erste Fremdsprache \\ (Dekret Juni 2008)}

- Kompetenzen:

- Hören

- Sprechen

- Lesen

- Schreiben

- Informationen über die Lebenswelt der Nachbarn erlangen

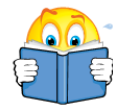

- Verständnisvoller Umgang mit kultureller Differenz

- Ziel in der Grundschule:

- Interesse und Neugier wecken

- Bewusstsein für Mehrsprachigkeit entwickeln

- Elementare Kommunikationsfähigkeit aufbauen

- Sprachliche Mittel und Strategien vermitteln

- Auch: Soziale Kompetenzen, Methodenkompetenzen 


\section{Rahmenplan: Französisch: Qualität der Unterrichtsgestaltung}

Orientierung am Gemeinsamen Europäischen Referenzrahmen für Sprachen

- Unterrichtssprache $=$ Zielsprache

- Alltagssituationen

- Vorrang Hören und Sprechen; Schreiben nur begrenzt

- Ziele: Schreiben und Lesen

- Erwerb von komplexeren Sprachmitteln

- Ermutigung durch angemessenen Bewertungen

- Entdeckung von Arbeitsmethoden und Lerntechniken

- Spielerische und künstlerische Herangehensweise MTTIVTIGN

\section{Förderungsprogramme}

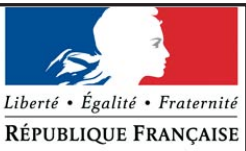

- 1. Kooperationsabkommen mit Frankreich (2000)

- Austausch von Studenten, Lehrern, Dozenten und Bildungsexperten

- Verbesserung der Kenntnisse der französischen Sprache und Kultur

- Weiterbildung im Fach Französisch - erste Fremdsprache für Kindergärtnerinnen, Primar- und Sekundarschullehrer

- Weiterbildung FORMAPRIM

- Weiterbildungsveranstaltungen über die französische Botschaft in Zusammenarbeit mit der Flämischen Gemeinschaft

- La Semaine du Film français 


\section{Schüler mit Migrationshintergrur}

- Übergangsklasse

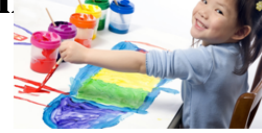

- insbesondere das Erlernen der Unterrichtssprache, um bestmöglich in das Alltagsleben integriert zu werden.

- Als neuankommende Schüler gelten Schüler, die folgende Bedingungen erfïllen:

- Sie sind zwischen 3 und 18 Jahre alt.

- Sie beherrschen nicht die Unterrichtssprache.

- Sie haben ihren Wohnsitz oder ständigen Aufenthaltsort in einer der neun Gemeinden der DG.

- Die Schule, in die sie sich einschreiben möchten, ist die nächstgelegene Unterrichtseinrichtung.

- Sie sind frühestens seit dem 1. Februar des vorhergehenden Schuljahres in einer Schule in der DG eingeschrieben.

- Übergangsklasse bis zum Ende des Schuljahres - unabhängig von der Ânzahl Schüler

- Dauer des Aufenthalts in der Übergangsklasse

Zusätzliche Informationen zum Bildungswesen in der Deutschsprachigen Gemeinschaft

- Ministerium der Deutschsprachigen Gemeinschaft

Abteilung Unterrichtswesen Gospertstraße 1

4700 Eupen

Belgien

Tel: $+32(0) 87.59 .63 .61$

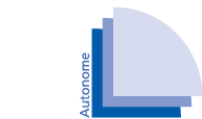

HOCHSCHULE

- Autonome Hochschule in der Deutschsprachigen

Gemeinschaft

Monschauer Straße 26

4700 Eupen

Belgien

Tel.: $+32(0) 87-590500$

Fax: +32(0) 87 - 556546 info@ahs-dg.be

Wichtige Informationen: www.unterrichtsverwaltung.be http://www.bild ungsserver.be

Wichtige Informationen: http://www.ahs-dg.be 


\section{Dr. Monika WitT}

\section{Situation der Deutschen Sprache im Oppelner Land und Umgebung}

Dr. Monika Witt, Pädagogische Hochschule Neisse/Nysa, Polen

Dr. Monika Witts Präsentation ,Situation der deutschen Sprache im Oppelner Land und Umgebung " befasst sich mit der Geschichte der deutschen Sprache in Schlesien - insbesondere in der Zeit seit 1990.

Dr. Monika Witt's presentation „Präsentation „Situation der deutschen Sprache im Oppelner Land und Umgebung" deals with the history of the German language in Silesia - especially during the period after 1990.

\section{Situation der deutschen Sprache im Oppelner Land und Umgebung}




\section{Schlesien vor 1945 Schlesien heute in den}

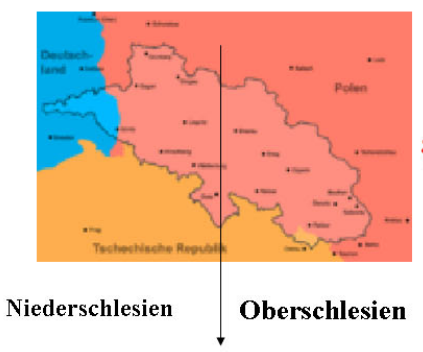

Grenzen der Tschechischen Republik

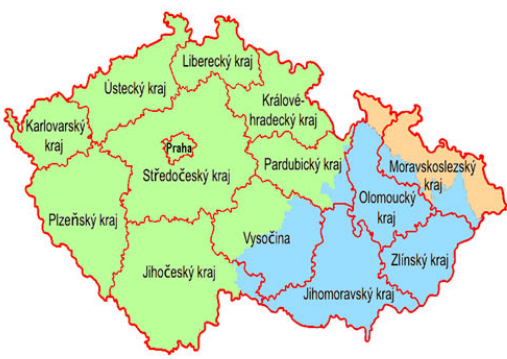

Rund 1,2 Millionen Deutsche sind 1945 in Oberschlesien geblieben. Viele von Ihnen sind später in den 70er und 90er Jahren ausgewandert, aber etwa $\underline{300} 000$ leben heute noch in Oberschlesien, obwohl die offizielle Zählung nach dem Referendum von 2002 nur etwa 140000 in ganz Schlesien ergab. Davon im Oppelner Land 106000 (10\% der Population).

\section{Schlesien heute: administrative Einteilung}

Woiwodschaft

Niederschlesien mit

Breslau/Wroclaw

Woiwodschaft

Oppeln/Opole

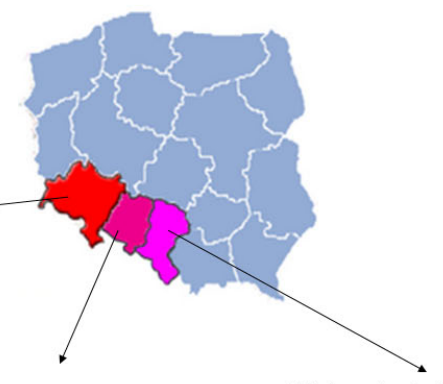

Woiwodschaft Schlesien mit Kattowitz 


\section{EUROREGION Altvater} mit u.a. der Stadt Neisse/Nysa

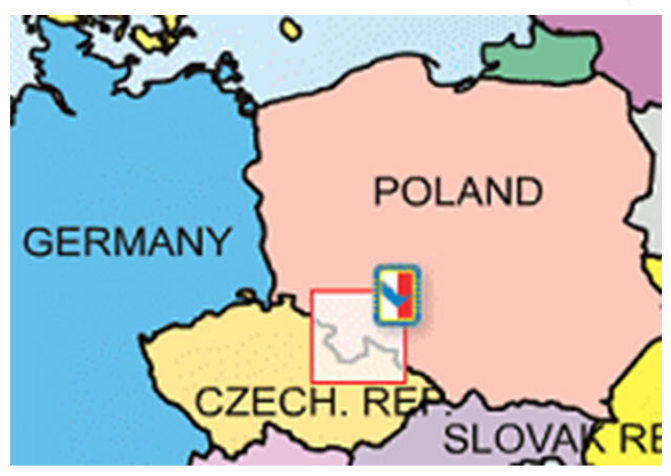

\section{Interkultureller Charakter von} Oberschlesien

[altes Grenzgebiet zwischen Polen Deutschland und Tschechien]

*außer Hochdeutsch wurde und wird hier auch ein polnischer Dialekt mit deutschen und mährischen lexikalischen und syntaktischen Elementen gesprochen (WASSERPOLNISCH)

*deutsche Mundarten, von denen heute nur die oberschlesische Mundart besteht, die aber nur von der Vorkriegsgeneration gesprochen wird.

Die junge Generation der zurückgebliebenen Oberschlesiern spricht im besten Falle Wasserpolnisch, Hochdeutsch und Standardpolnisch. 


\section{Oberschlesien: Gemeinden mit deutscher Bevölkerung}

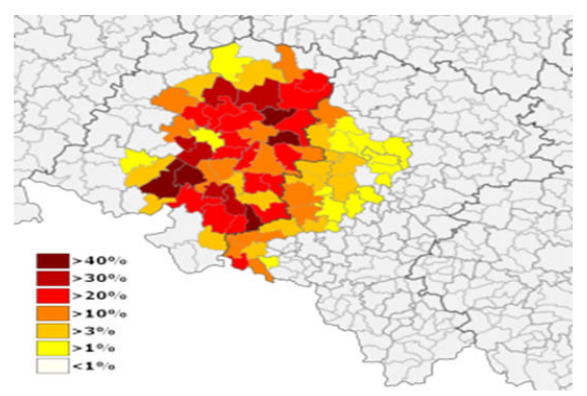

\section{Die Situation Anfang 1990}

Die Wiederbelebung der deutschen

Sprache als Mutter- und Fremdsprache

${ }^{*}$ Schulen

*Medien

*Behörden

*Kirchen

*Kulturelle Einrichtungen

*Politische Gruppierungen 


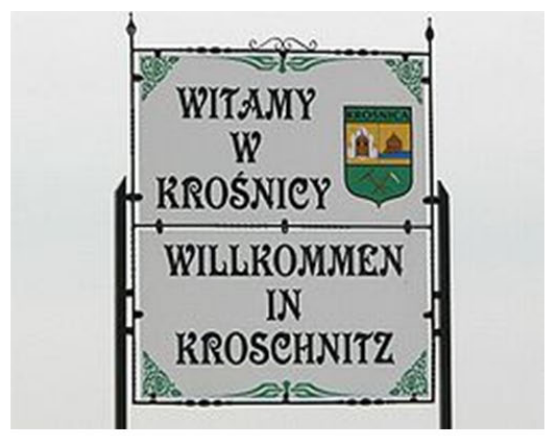

Bis 2005 haben etwa 288.000 Bürger in Polen, insbesondere in Oberschlesien und Masuren, die Bestätigung des deutschen Konsulats erhalten, von Geburt an die deutsche Staatsbürgerschaft zu besitzen.

\section{Schulwesen \\ Deutsch als Muttersprache \\ - Oppelner Land \\ 1. Kindergärten}

liczba przedszkoli

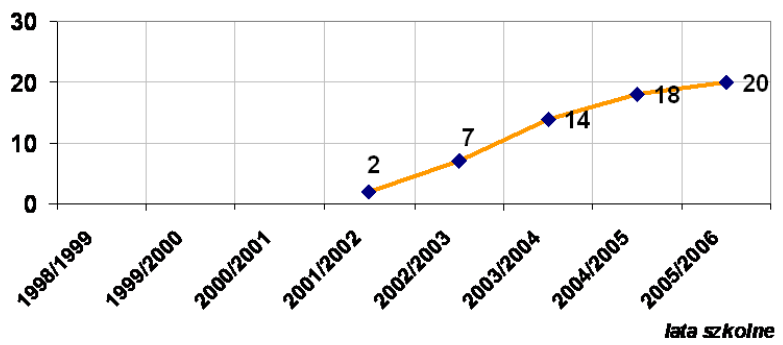




\section{Schulwesen \\ Deutsch als Muttersprache \\ - Oppelner Land}

1. Grundschulen

liczba szkół podstawowych
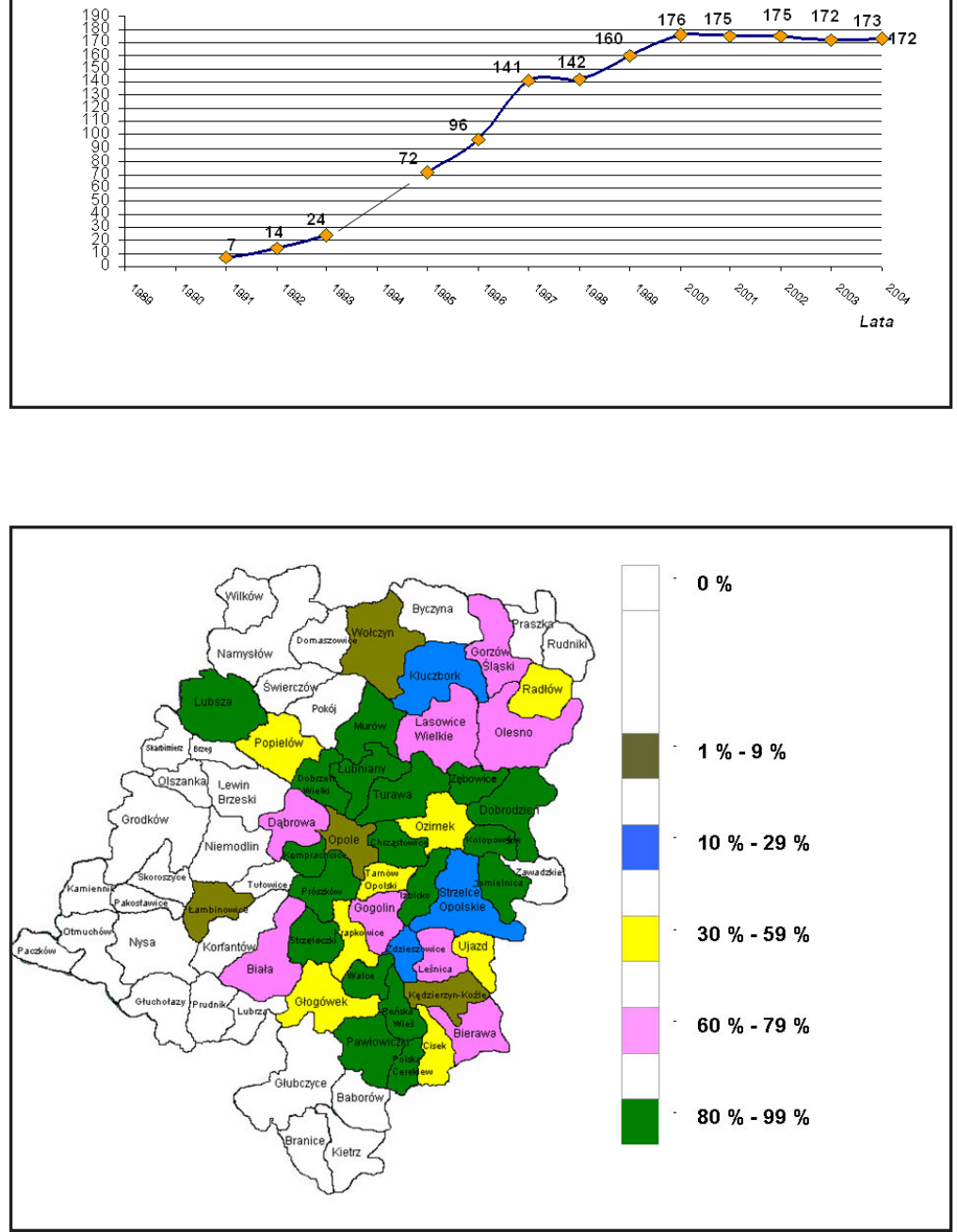


\section{Deutsch als Muttersprache: Mittelschulen (Gymnasien)}

liczba gimnazjów

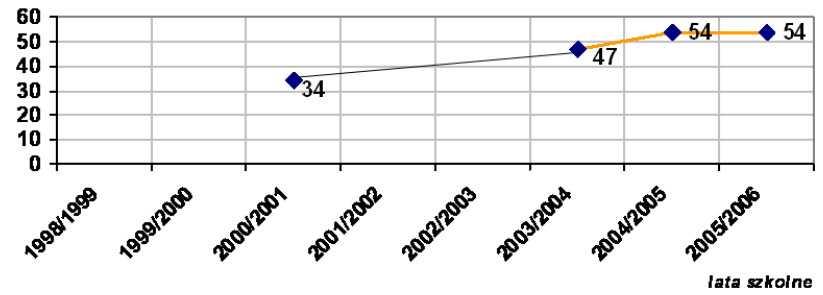

\section{Oberschulen [Lyzeen, Technika]}

Kein Unterricht „Deutsch als Muttersprache” dafür aber funktionieren an 7 Oberschulen im Oppelner Land zweisprachige Klassenzüge mit Deutsch 


\author{
AdAm MorcineK \\ Literarische Spaziergänge durch Neisse
}

Adam Morcinek, Student an der Universität Neisse/Nysa, Polen

In seinem Projekt „Literarische Spaziergänge durch Neisse“ nimmt uns Adam Morcinek auf literarisch-historische Spaziergänge durch Neisse mit. Aufgrund der interaktiven Gestaltung wurde auf eine ausführliche gedruckte Darstellung verzichtet, da sie dem Projekt nicht gerecht geworden wäre. Die kompletten Spaziergänge sind im Internet unter http://www.spaceryliterackie.pwsz.nysa.pl/ zu finden.

In his project „Literarische Spaziergänge durch Neisse“ Adam Morcinek takes us on literary and historical walks through Nysa. Due to the interactive layout, a detailed printed representation was not attempted because it would not have done the project justice. The complete walks can be found on the internet:

http://www.spaceryliterackie.pwsz.nysa.pl/ . 

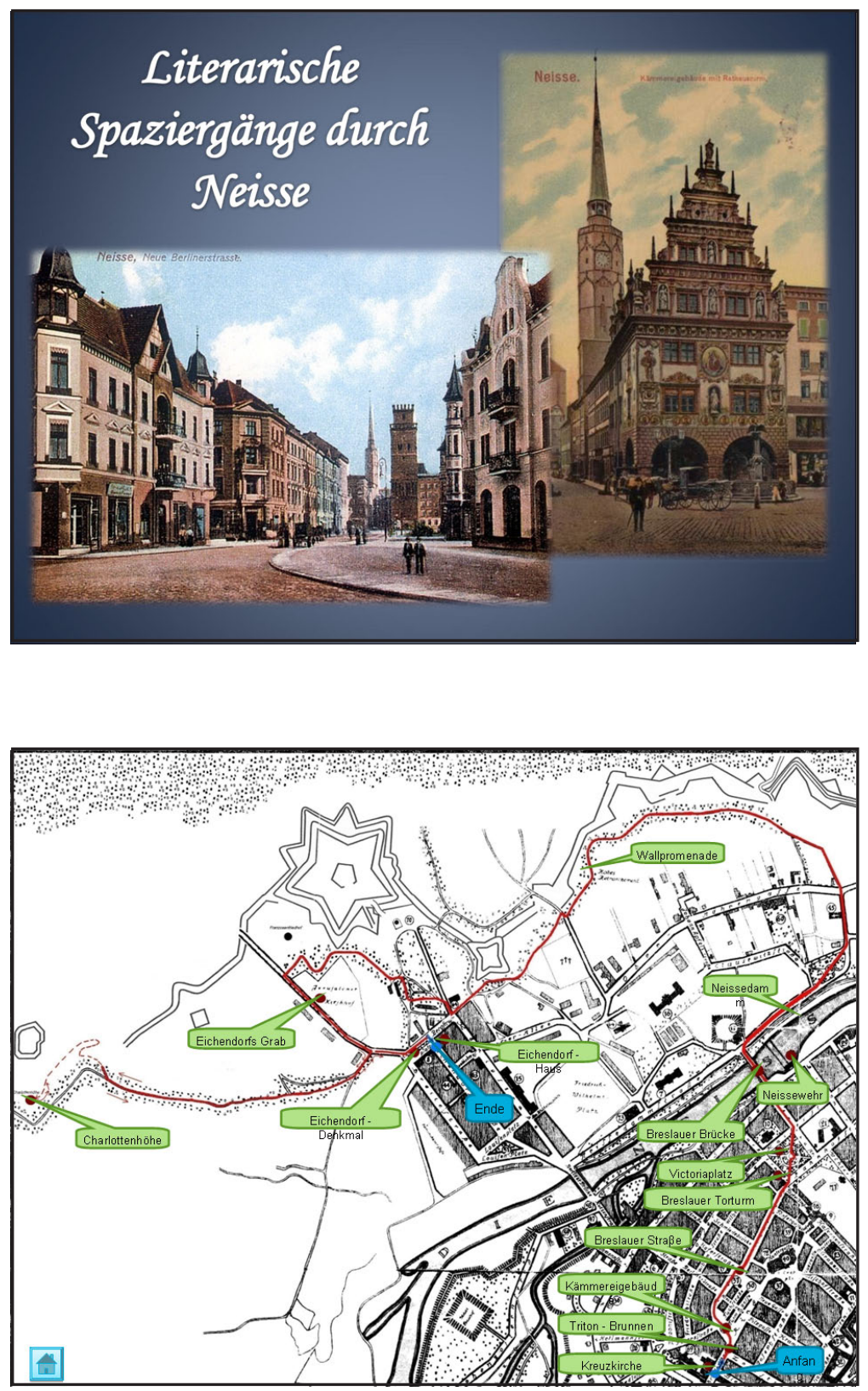


\section{MoniKa MoscheK}

\section{Deutschunterricht im Kindergarten}

Monika Moschek, Studentin an der Universität Neisse/Nysa, Polen

In ihrer Präsentation „Deutschunterricht im Kindergarten“ beschäftigt sich Monika Moschek mit dem frühen Erlernen einer Fremdsprache, dessen Vorzügen und Voraussetzungen. Da die Präsentation viele Fotos enthält, die im Schwarzweißdruck nur unzureichend zur Geltung kommen würden, sind hier nur die Kernaussagen wiedergegeben. Die komplette Präsentation kann im Internet unter http://www.uni-kassel.de/fb1/lesenundschreiben/abgerufen werden.

In her presentation „Deutschunterricht im Kindergarten“ Monika Moschek specializes on the early learning of a foreign language, its merits and requirements. Only the core statements are mentioned here since the presentation contains many photos which would only insufficiently show in monochrome print. The complete presentation can be accessed via internet:

\section{http://www.uni-kassel.de/fb1/lesenundschreiben/.}




\section{Wie und warum lernen Erwachsene Fremdsprachen???}

1.Rational, brauchen logische Erklärungen

2. Meistens aus beruflichen Gründen

\section{Was ist wichtig im Fremdsprachenunterricht für Kinder???}

- Lernen durch spielen

- Verschiedne Aktivitäten

- Authentische Lehrmittel

- Wiederholungen

- Regelmässige Pausen

- Benutzung der FS in Altagssituationen

- Lusterweckung

- Kleine Gruppen

- Keine Kritik, aber auch kein Mitleid

- Ausstatung des Raumes 


\section{INES ToBIS}

Neue Möglichkeiten des Programms

Lifelong Learning

Ines Tobis, Akademisches Auslandsamt der Universität Kassel

In ihrer Präsentation „Neue Möglichkeiten des Programms Lifelong Learning" spricht Ines Tobis vom Akademischen Auslandsamt der Universität Kassel über das EU-Bildungsprogramm LLP mit besonderem Schwerpunkt auf dem ERASMUS Austauschprogramm

In her presentation „Neue Möglichkeiten des Programms Lifelong Learning" Ines Tobis from the International Office talks about the educational program of the EU (LLP). Her special focus is on the ERASMUS exchange program.

\section{Gliederung}

- Struktur des Programms Lifelong Learning (LLP)

- Zentrale und Dezentrale Maßnahmen des

ERASMUS-Programms

- ERASMUS Placements

- Intensivprogramme

- Schwerpunktprogramme LLP

- ERASMUS an der Uni Kassel

Universităt Kassel - Abteilung Kommunikation und Internationales 


\section{Das EU-Bildungsprogramm: LLP 2007 - 2013}

Programm

für Lebenslanges Lernen 2007 - 2013

\begin{tabular}{|c|c|c|c|c|}
\hline \multicolumn{4}{|c|}{ Budget: 6,97 Mrd. EUR } & \\
\hline Mind. $13 \%$ & Mind. $40 \%$ & Mind. $25 \%$ & Mind. $4 \%$ & \\
\hline $\begin{array}{l}\text { Schulbildung } \\
\text { COMENIUS }\end{array}$ & $\begin{array}{l}\text { Hochschul- } \\
\text { bildung } \\
\text { ERASMUS } \\
\text { 3,1 Mrd. EUR }\end{array}$ & $\begin{array}{c}\text { Berufliche } \\
\text { Aus- und } \\
\text { Weiterbildung } \\
\text { LEONARDO } \\
\text { DA VINCI }\end{array}$ & $\begin{array}{l}\begin{array}{c}\text { Erwachsenen- } \\
\text { bildung }\end{array} \\
\text { GRUNDTVIG }\end{array}$ & $\begin{array}{l}\text { ab } 2009 \\
\text { Erasmus } \\
\text { MUNDUS }\end{array}$ \\
\hline \multicolumn{4}{|c|}{$\begin{array}{l}\text { Querschnittsprogramme/ } \\
\text { Jean Monnet }\end{array}$} & \\
\hline
\end{tabular}

Universităt Kassel - Abteilung Kommunikation und Internationales

\section{Dezentrale Maßnahmen: ERASMUS}

- Studierendenmobilität

- Studierenden-Praktika

- EILC-Sprachkurse

- Intensivprogramme

- Dozentenmobilität

- Personalmobilität

a. auch an außeruniversitäre Einrichtungen

b. auch Einladung von Unternehmenspersonal 


\section{Zentrale Maßnahmen: ERASMUS}

- Multilaterale Projekte (3 Institutionen aus 3 Ländern)

- Curriculum development

- Virtual Campuses

- Modernisation of Higher Education

- Cooperation between Higher Education and Enterprises

- Netzwerke (31 Institutionen aus 31 Ländern)

- Akademische Netzwerke

- Strukturelle Netzwerke

- Begleitende Maßnahmen

Universität Kassel - Abteilung Kommunikation und Internationales

\section{Dezentrale Maßnahme ERASMUS Placements:}

- Vollzeitpraktikum

- Studienbezug des Praktikums

- Mindestens 3 Monate, maximal 12 Monate

- $300-350 €$ pro Monat

- Organisatorische Unterstützung vor dem Praktikum

- Zertifikat über die Teilnahme am Programm 


\section{Dezentrale Maßnahme ERASMUS Placements:}

- Staatsbürgerschaft eines der ERASMUS-Länder oder Anerkennung als Flüchtling, Staatenloser oder als ständig wohnhaft in Deutschland

- Immatrikulation während des Praktikums an der Uni Kassel

- Bewerbungsfrist: 3 Monate ohne Praktikumsplatz, 1 Monat mit Praktikumsplatz

\section{Dezentrale Maßnahme Intensivprogramme (IP)}

- Sommerschulen oder Blockseminare

- Mind. 10 Tage (am Stück), max. 6 Wochen

- Hochschulen aus mind. 3 verschiedene ERASMUS-Teilnehmerländer (Neue Beitrittsländer!)

-BA, MA und PhD

- Auch Förderung von Nicht-EU-Studierenden! 


\section{Dezentrale Maßnahme Intensivprogramme (IP)}

- Interdisziplinär und innovativ:

$>$ Neue fachliche Herangehensweisen

$>$ Didaktische Methoden

$>$ Perspektive für Curriculums-Entwicklung

- Europäischer Kontext

- Akademische Anerkennung der Studienleistungen

\section{Dezentrale Maßnahme Intensivprogramme (IP)}

- Mind. 10 ausländische Studierende

- Max. 60 Studierende insgesamt

- Max. 20 Dozenten

- Zuschüsse zu den realen Fahrtkosten der Studierenden und Dozenten

- Pauschaler Zuschuss zu den Aufenthaltskosten

- Pauschaler Zuschuss zu den Organisationskosten 


\section{Schwerpunktprogramme LLP}

- Projekte, die einen Querschnitt über die

Programme COMENIUS, ERASMUS, LEONARDO und GRUNDTVIG bilden

- Teilprogramme zu Sprachen, IKT-Maßnahmen und

Verbreitungsaktivitäten

Universităt Kassel - Abteilung Kommunikation und Internationales

\section{Partnerhochschulen der Uni Kassel: www.uni-kassel.de/aaa/Partner.htm}

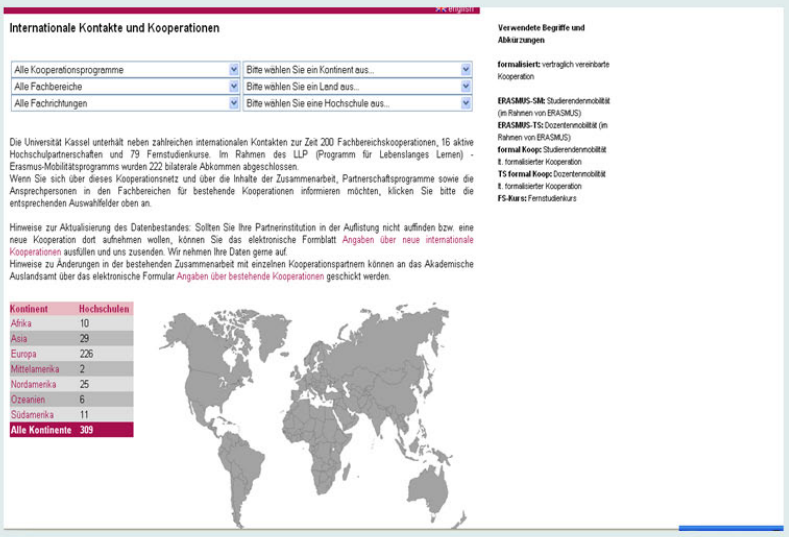




\section{ERASMUS outgoing students 2000-2006: zentrale Länder}

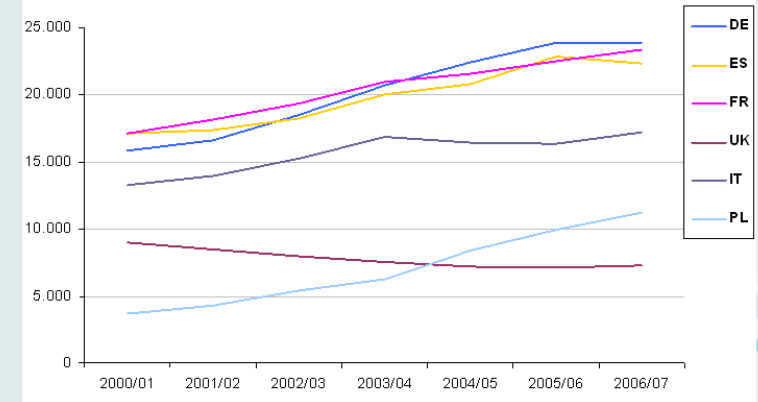

Universităt Kassel - Abteilung Kommunikation und Internationales

\section{Mobilität deutscher Studierender (Outgoings) 1987 - 2006}

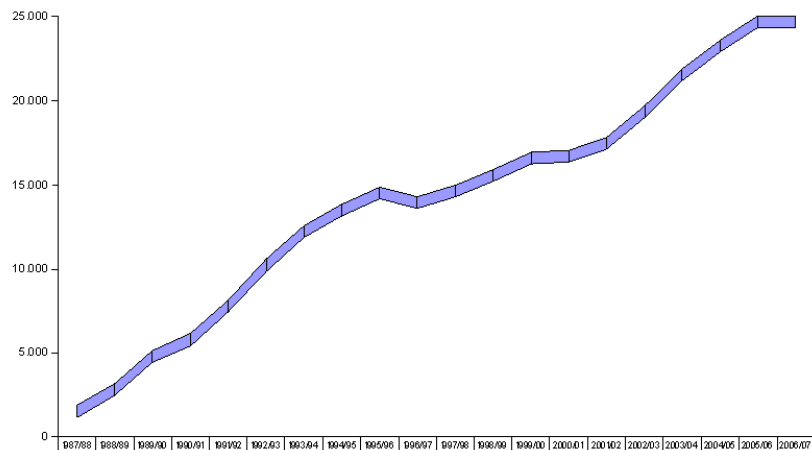

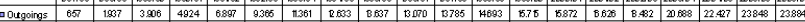

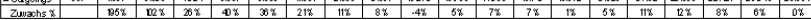




\section{Incomings nach Deutschland aus den $\mathbf{4}$ größten Partnerländern}

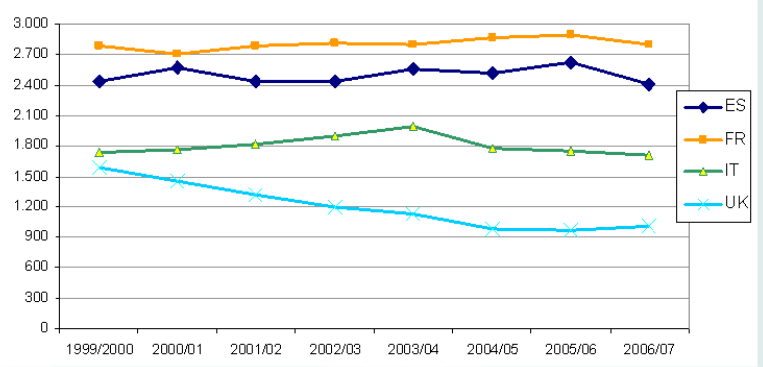

\section{ERASMUS-Studierende der Universität Kassel}

(Outgoing) 2000 - 2008

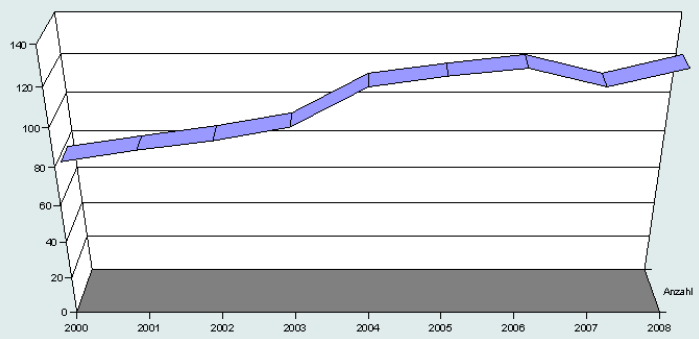




\section{Outgoing students der Uni Kassel} nach Ländern (2007/08)

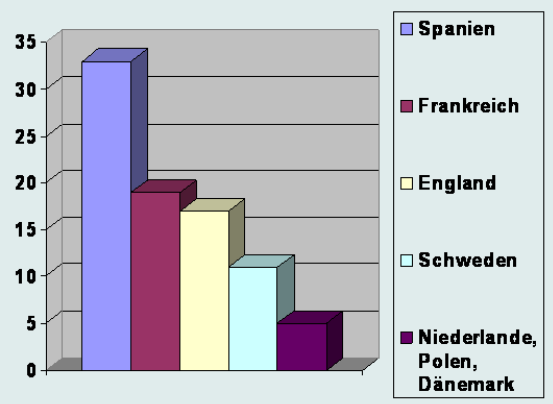

Universităt Kassel - Abteilung Kommunikation und Internationales

\section{Incoming students an der Uni Kassel} nach Ländern (2007/08)

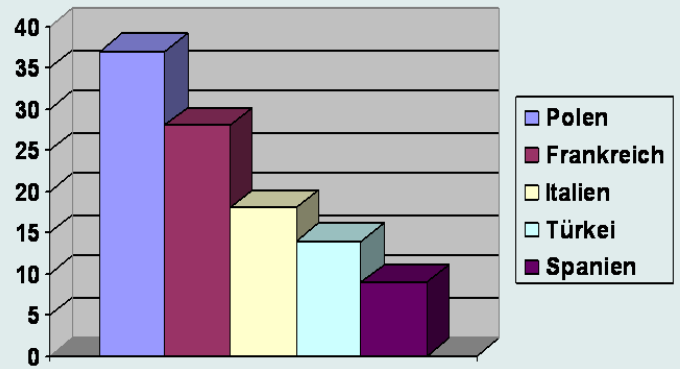




\section{Michael KoENIG}

Das Fachgebiet Deutsch als Fremdsprache / Zweitsprache an der Universität Kassel - Konzepte und Inhalte

Michael Koenig, Universität Kassel, Fachgebiet DAFZ

In seiner Präsentation „Vorstellung des Fachgebiets Deutsch als Fremd- und Zweitsprache / Universität Kassel“ beschreibt Michael Koenig den Aufbau des Masterstudiengangs DaFZ (Deutsch als Fremdsprache / Deutsch als Zweitsprache).

In his presentation „Vorstellung des Fachgebiets Deutsch als Fremdund Zweitsprache / Universität Kassel“" Michael Koenig describes the structure of the masters program for German as a foreign / German as a second language.

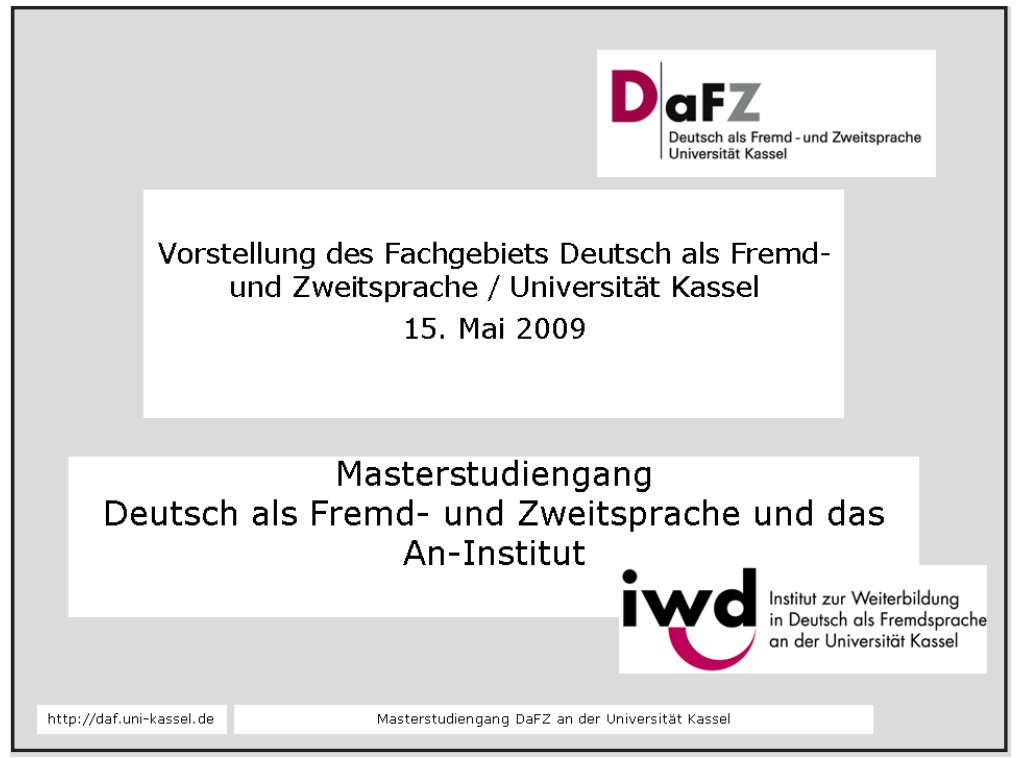




\section{Formalia}

Bewerbungsschluss: jeweils 15. Juli

Studienbeginn: jeweils im Wintersemester

Voraussetzungen: berufsqualifizierender Hochschulabschluss mit mindestens 6 Semestern in den Fächern, Deutsch, Germanistik, Deutsch als Fremdsprache oder einem anderen sprachbezogenen Fach

sehr gute deutsche Sprachkenntnisse (DSH 2-3, TestDaF 4-5 oder gleichwertige Prüfung)

Regelstudienzeit: $\quad 4$ Semester

Leistungspunkte: $\quad 120$ Credits $(=30$ Credits pro Semester)

\section{Profil des Masterstudiengangs DaFZ}

Das Masterstudium Deutsch als Fremd- und Zweitsprache an der Universität Kassel konzentriert sich auf Theorie und Praxis des fremd- und zweitsprachlichen Deutschunterrichts und dessen empirischer Erforschung.

Die Verzahnung vertiefender wissenschaftlicher Ausbildung mit unterrichtspraktischer und forschungsorientierter Ausrichtung ist daher profilbildend für den Kasseler Masterstudiengang DaFZ. 


\section{Ziele des Masterstudiengangs DaFZ (I)}

- Kenntnis aktueller Entwicklungen in der Fremdsprachenlehrund -lernforschung sowie in der Fremd- und Zweitsprachendidaktik

- Fähigkeit, diese Entwicklungen im Hinblick auf ihre Relevanz sowohl für das Fach als auch für den Deutsch als Fremd- und Zweitsprache-Unterricht angemessen einzuschätzen

- Fähigkeit zum reflektierten Umgang mit unterschiedlichen unterrichtsmethodischen Ansätzen

\section{Ziele des Masterstudiengangs DaFZ (II)}

- Sensibilisierung für den reflektierten Umgang mit heterogenen Lernergruppen und Entwicklung interkultureller Kompetenzen

- Fähigkeit zum reflektierten Umgang mit kulturell geprägten Lehr- und Lernerfahrungen

- Kenntnis und angemessene Anwendung von Forschungsmethoden

- Fähigkeit zur selbständigen wissenschaftlichen Arbeit: kritische Rezeption fachwissenschaftlicher Publikationen und eigenständige Konzeption wissenschaftlich relevanter Fragestellungen 


\section{Curriculum}

Das Masterstudium DaFZ umfasst einen Pflichtbereich und einen Wahlpflichtbereich.

Der Pflichtbereich besteht aus drei Basismodulen (BM1BM3), zwei Anwendungsmodulen (AM1 und AM2) sowie einem Mastermodul (MM).

Der Wahlpflichtbereich besteht aus vier Vertiefungsmodulen (VM1 - VM4).

\section{Pflichtbereich: Basismodule}

Der Pflichtbereich umfasst die folgenden Module:

- Basismodul 1 (BM1):

Grundlagen des Fachs in Theorie und Praxis (10 credits)

- Basismodul 2 (BM2):

Erwerb und Vermittlung von Fremd- und Zweitsprachen (10 credits)

- Basismodul 3 (BM3):

Fortgeschrittene wissenschaftliche Kompetenzen (10 credits)

$\rightarrow$ insgesamt: 30 credits

Die Basismodule sind im 1. Semester zu absolvieren. 


\section{Pflichtbereich: Anwendungsmodule}

- Anwendungsmodul 1 (AM1):

Unterrichtspraktikum (10 credits)

- Anwendungsmodul 2 (AM2):

Forschungsprojekt (10 credits)

$\rightarrow$ insgesamt: 20 credits

Die Anwendungsmodule sind im 2. und 3. Semester zu absolvieren.

\section{Wahlpflichtbereich: Vertiefungsmodule (I)}

Der Wahlpflichtbereich umfasst die folgenden Module:

- Vertiefungsmodul 1 (VM1): Planungsgrundlagen für den Unterricht $D a F / D a Z$ (10 credits)

- Vertiefungsmodul 2 (VM2): Gegenstände des Unterrichts DaF/DaZ (10 credits)

- Vertiefungsmodul 3 (VM3): Mediale Lernumgebungen (10 credits) 
Wahlpflichtbereich: Vertiefungsmodule (II)

- Vertiefungsmodul 4 (VM4):

Aktuelle Trends und Entwicklungen (10 credits)

$\rightarrow$ insgesamt: 40 credits

Die Vertiefungsmodule sind im 2. und 3. Semester zu absolvieren.

\section{Mastermodul}

Das Mastermodul umfasst die Anfertigung der Masterarbeit, den Besuch eines Begleitkolloquiums sowie die Absolvierung eines Prüfungskolloquiums.

$\rightarrow$ insgesamt 30 credits

Das Mastermodul ist im 4. Semester zu absolvieren. 


\section{Prüfungsleistungen (I)}

Prüfungsleistungen werden in der Regel benotet (Ausnahme: $B M 1$ ) und in einer der folgenden Formen erbracht:

- Klausuren von 90 Minuten (BM1 und BM2)

- Portfolios ( $B M 1$ unbenotet; $B M 3$ benotet)

- Mündliche Kurzpräsentationen (BM3)

- Schriftliche Hausarbeiten im Umfang von 15 bis 20 Seiten oder eine vergleichbare Leistung in einer anderen medialen Form (VM1, VM3)

\section{Prüfungsleistungen (II)}

- Referate mit einer Dauer von 20-30 Minuten mit schriftlicher Ausarbeitung im Umfang von ca. 8 Seiten (VM2)

- Mündliche Einzelleistungen von 30 Minuten Dauer (VM2)

- Schriftliche Berichte im Umfang von 10-15 Seiten (AM1, AM2, VM4)

- Online-Tests (VM4) 


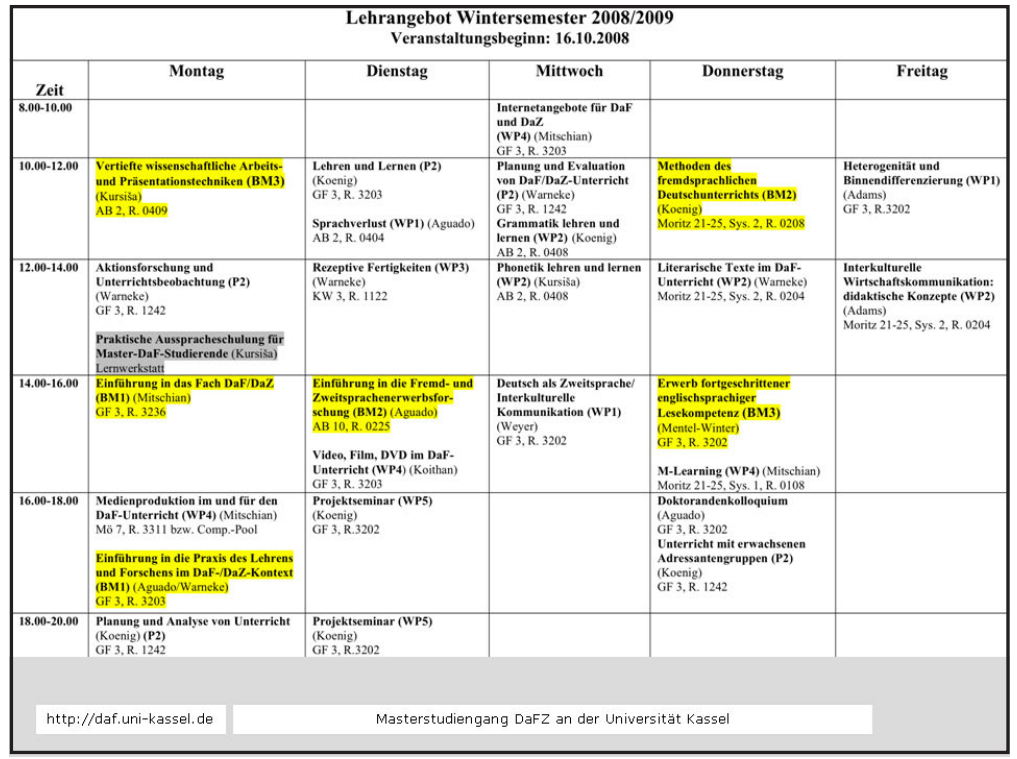

Prüfungsleistungen im Wintersemester 2008/09

- 2 Klausuren von 90 Minuten ( $B M 1$ und $B M 2$ )

- 2 Portfolios (BM1 unbenotet; $B M 3$ benotet)

- 3 mündliche Kurzpräsentationen ( $B M 3$ ) 

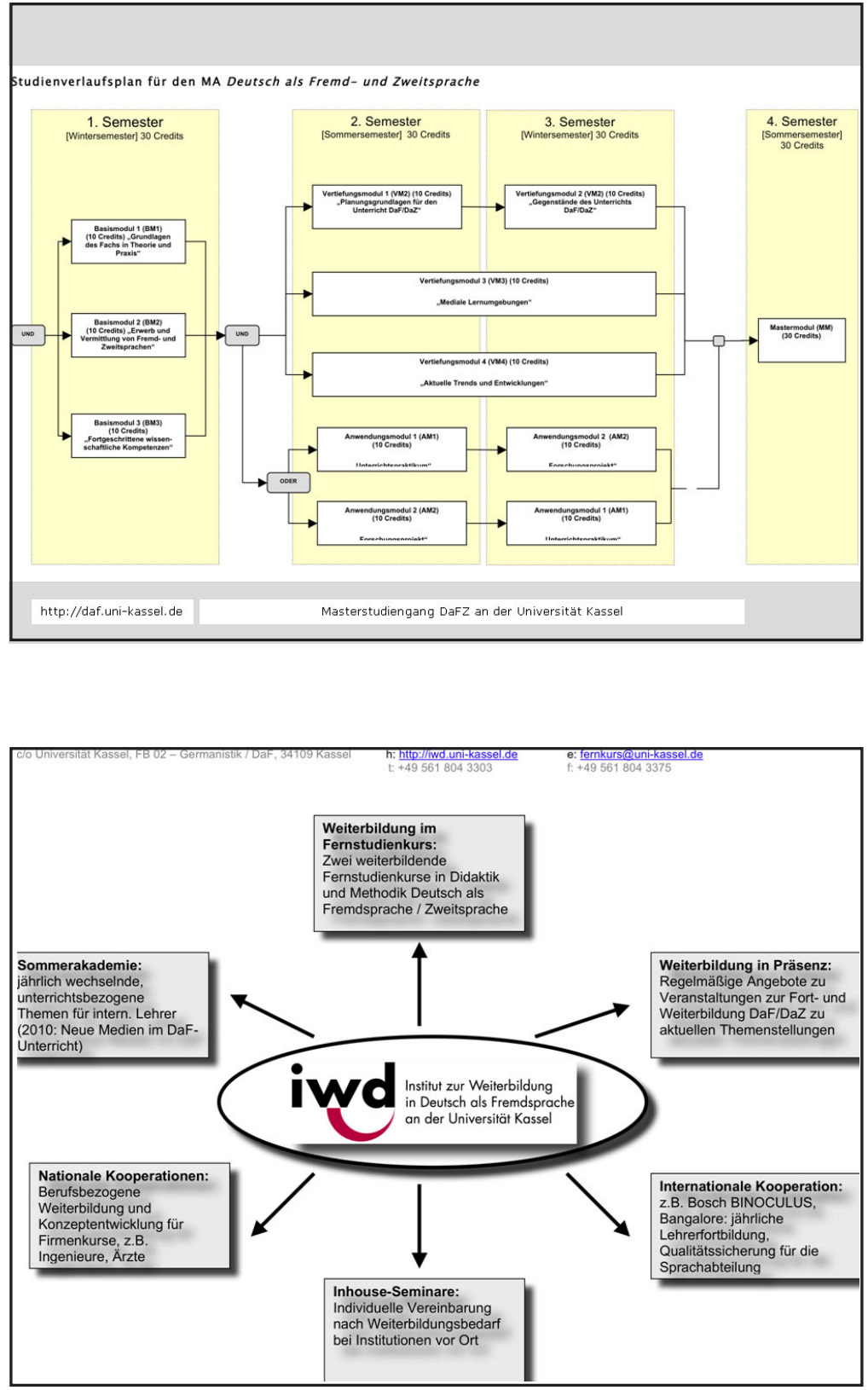


\section{Anwendungsmodul: Forschungsprojekt}

\section{Videokonferenz \\ AM2}

Prof. Dr. H. Mitschian

m

\section{Forschungsprojekt "Videokonferenz"}

Germanistik-Studenten der Zhejiang Universität in Hangzhou/VR China stellen ihre Abschlussarbeiten per Videokonferenz vor. Die Masterstudenten im Studiengang DaF/Z der Universität Kassel analysieren die Vorträge und schlagen ihren Partnern in China Verbesserungen in sprachlicher oder inhaltlicher Art vor.

Themen der Vorträge:

- Unterschiede und Analyse der Konsumkultur und -struktur zwischen chinesischen und deutschen Studentinnen

- Wechselwirkungen zwischen Werbung und Massenkultur

- Einflüsse großer Sportveranstaltungen auf den lokalen Tourismus am Beispiel FIFA-WM 2006 in Deutschland und der Olympiade 2008 in Beijing

- Die Entwicklung deutscher Aktiengesellschaften nach dem Zweiten Weltkrieg und deren Einfluss [auf China] Methoden des Wortschatzlernens

- Deutschland als Vorbild für China:

- Anregungen aus dem deutschen „Wirtschaftskreis $\mathbf{V}$ lauf- und Abfallbewirtschaftungsgesetz“ für die Entwick $\mathbf{T l u n g}$ des Wirtschaftskreislaufs in China

- Warum ist Deutschland für chinesische Unternehmen das Messeland erster Wahl?

- Die deutsche Politik des Finanztransfers und ihre Übertragbarkeit auf die chinesische Finanzpolitik

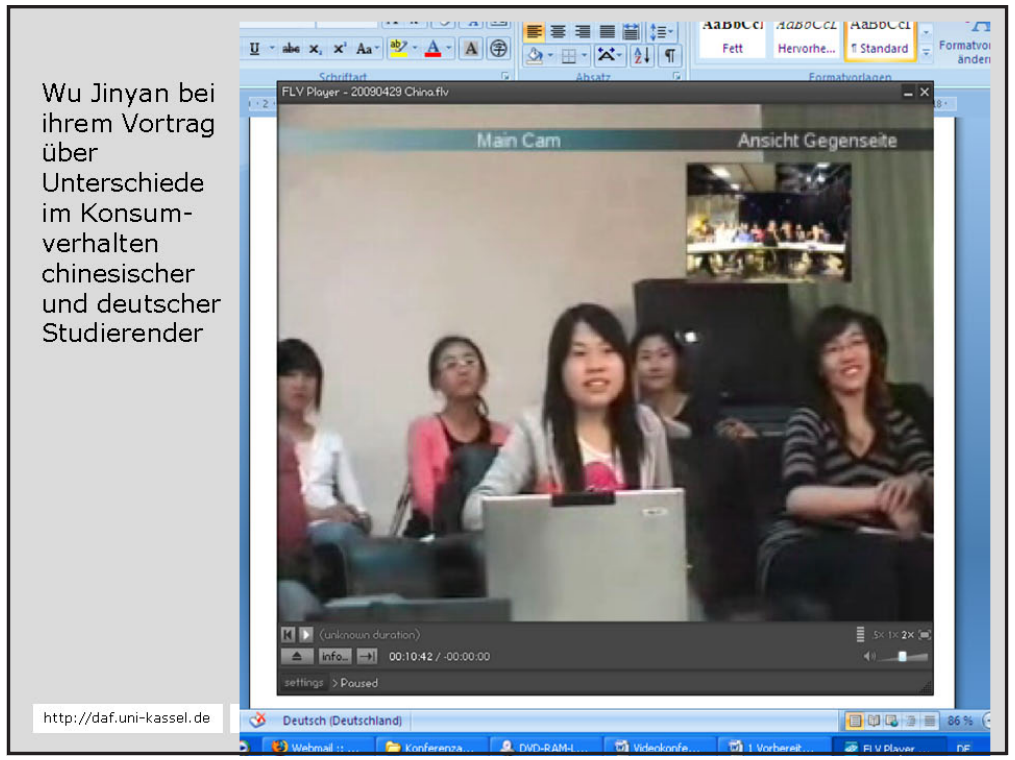




\begin{tabular}{|c|c|}
\hline & $\begin{array}{l}\text { Teilprojekt B: Maßnahmen zur Verbesserung der englischen Sprachkompetenz von Studierenden } \\
\text { Zur Verbesserung der fachspezifischen fremdsprachlichen Kommunikationsfähigkeit der Studierer } \\
\text { und zur Unterstützung der Kommunikation in Lehrveranstaltungen wird ein On } \\
\text { Formulierungswörterbuch (OFW), das durch Studierende und Lehrende fortlaufend ergänzt we } \\
\text { kann, entwickelt und evaluiert. Das OFW wird zunächst in einer Basisversion für die Sprachen Dey } \\
\text { und Englisch erstellt und soll anschließend um eine dritte Sprache, die eine der quantitativ releva } \\
\text { Herkunftssprachen der Studierenden ist, ergänzt werden. } \\
\text { Im Rahmen von Teilprojekt B wird außerdem überprüft, ob durch neu zu entwickelnde "Star } \\
\text { Veranstaltungen die Probleme deutscher und internationaler Studierender mit englischsprach } \\
\text { Lehre verringert werden können. Die "Starter“-Veranstaltungen sind als englischspraa } \\
\text { fachwissenschaftliche Lehrveranstaltungen konzipiert, in die während der ersten Wochen } \\
\text { Erweiterung der Fremdsprachenkompetenz systematisch integriert ist. Dabei wird besonderer } \\
\text { auf die Entwicklung der Fähigkeit zum selbstständigen Umgang der Studierenden } \\
\text { fremdsprachlichen Problemen und zur selbstständigen Weiterentwicklung } \\
\text { Fremdsprachenkompetenz gelegt. } \\
\text { Ein Teil des „Starter“-Programms Englisch soll auch mit internationalen Studierenden in überwie } \\
\text { deutschsprachigen Lehrveranstaltungen erprobt werden, denn die auch dort erforderliche Rezen } \\
\text { von Fachliteratur in englischer Sprache - teilweise in erheblichem Umfang - bedeutet für } \\
\text { internationale Studierende die Verwendung einer zweiten Fremdsprache im Studium und damit } \\
\text { zusätzliche Belastung und Hürde. }\end{array}$ \\
\hline
\end{tabular}

\section{DaZ-Projekt \\ Die Berücksichtigung des "DaZ-Aspektes" in Deutsch als Fremdsprachelehrwerken}

Projektseminar

Fachgebiet: $\mathrm{DaF} / \mathrm{Z}$

Seminarleiter: Michael

Koenig

WS $08 / 09$

Datum: 10.02 .2009
Thi Thu Suong Dang

Mehmet Can Sander

Sarasi Kannangara

Thi Thu Trang Tran

Anna Morozova 


\section{ZIELE:}

- A: Festzustellen, ob der DaZ-Aspekt in den DaF-Lehrwerken und $u$. a. bei den Sprachinstitutionen in Kassel berücksichtigt wird

- B: Die Lehrwerke auf ihre Qualität und Effektivität im Unterricht zu analysieren

- C: Verbesserungsvorschläge für die Sprachinstitutionen, evt. an Verlage anzubieten.

\section{BENUTZTEN LEHRWERKE:}

- Institut für Sprachen (IfS):

\section{IfS}

Studio D

- Volkshochschule (Phillip-Scheidemann-Haus): Berliner Platz

- Dialog Institut: Plus Punkt Deutsch/

Themen aktuell

- DSI: Berliner Platz
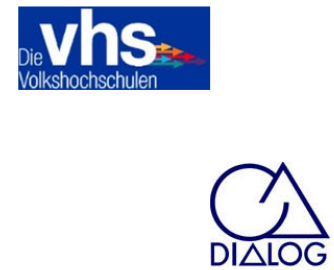

\section{Das SpracheninstitutDS|}




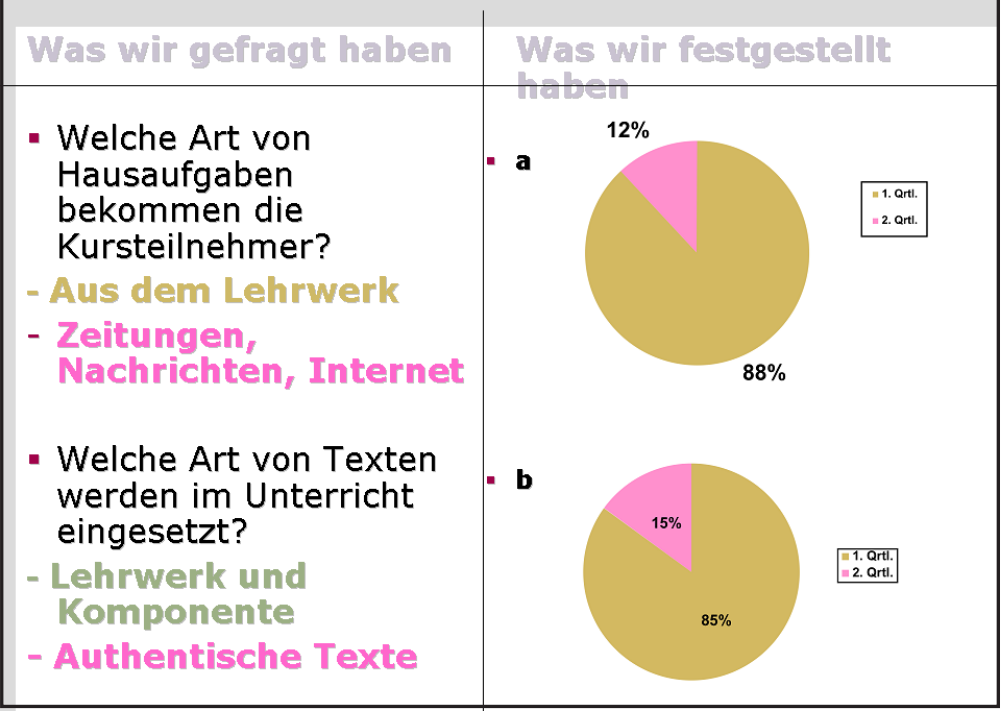

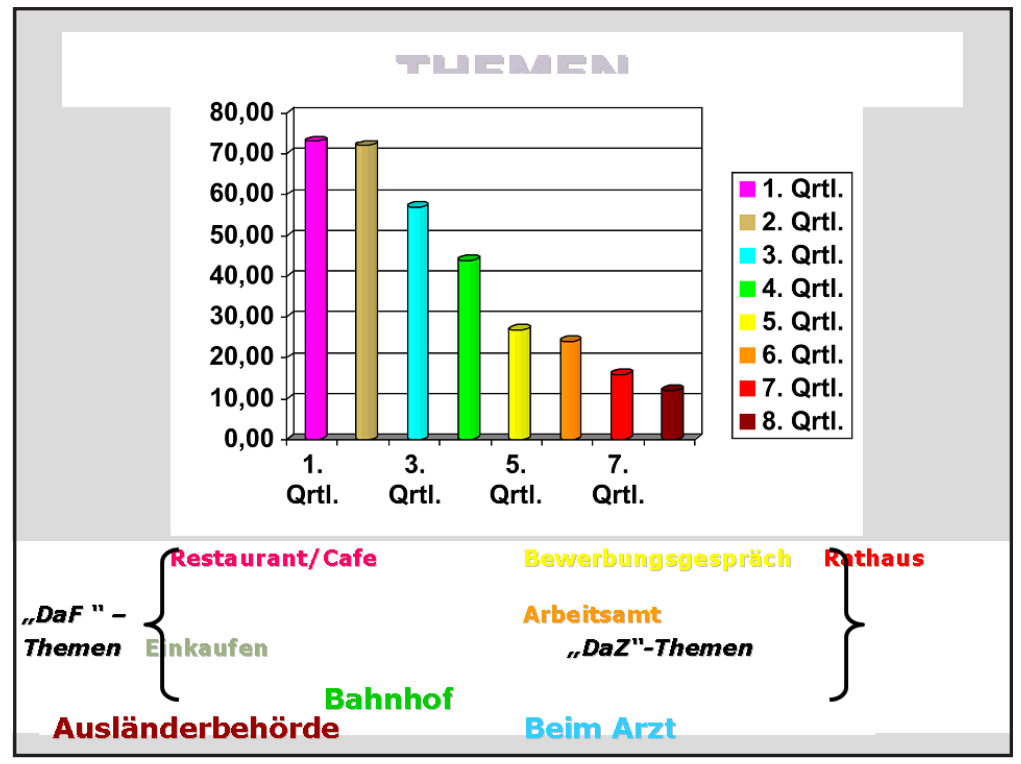




\section{UNTERRICHTSPRAKTIKUM IM FACHGEBIET DAF/DAZ IN KASSEL}

- Aktionsforschung

- Basisseminar Lehren und Lernen (Prinzipien und Micro-teaching)

- Hospitationen

- Begleitseminar I (Planung von konkreten Unterrichtsvorhaben und Unterrichtsversuchen

- Durchführung des Unterrichts und Videografie

- Begleitseminar II (Analyse von Unterrichtsvideos)

Analyse und Erstellung von Lehrmaterialien

\section{MEHRSPRACHIGKEIT IN}

\section{LEHRWERKEN}

Affaire d'amour für die Zunge.

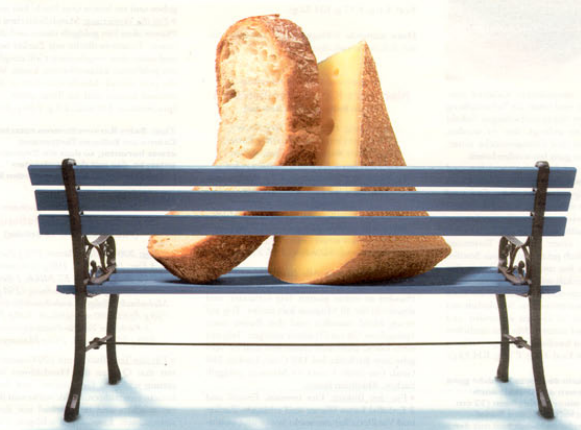




\section{EUROPANTO \\ Toto et sa litule sorella}

Die Mutter of Toto lui demande to go shopping $y$ lui donne una liste de things zu kaufen. Seine mamma le dice auch: „Nimm tua little sorella mit !“”

Toto geht in das magasin, kauft todas things, aber quando er herauskommt, seine little sorella falls dans un Loch y disappears.

Quando Toto arrive at home, seine Mutti le dice: „Wo ist ta little sorella?“"

Toto answers:

„Elle est dans un Loch gefallen."

„Aber por qué du hast her nicht helped to sortir?" dice la mother.

„Porque it was not aufgeschrieben sur la Liste!“ answers Toto.

\section{EUROPANTO (SCHÜLERTEXT)}

It's Pierre und Jean qui entrano in ein Bulding.

Pierre sagt : Appelle the ascenseur. Ascensore! Elevator! schreit Jean.

\section{Rébecca}




\section{EUROPANTO (SCHÜLERTEXT MIT DT. ,ÜBERSETZUNG')}

Une little Mädchen goes in einen magasin zoologique. She fragt:" Can ich avoir a perroquet for my little frère? " La Frau antwortet:" No, wir ne tauschen pas. "

Ein kleines Mädchen geht in einen zoologischen Laden. Sie fragt: "Kann ich ein Papagei für meinen kleinen Bruder haben? „Die Frau antwortet:" Nein wir tauschen nicht. " 


\section{HARUn OSMANI}

\section{Mehrsprachigkeit als Chance}

Harun Osmani, Pädagogischer Koordinator des Muttersprachenunterrichts Region Vantaa, Finnland

In seiner Präsentation zum Workshop „Mehrsprachigkeit als Chance" stellt Harun Osmani die finnische Stadt Vantaa vor und beschreibt den freiwilligen Muttersprachenunterricht für Migrantenkinder an den dortigen Schulen.

In his presentation for the workshop „Mehrsprachigkeit als Chance" Harun Osmani introduces the Finnish city of Vantaa and describes the voluntary lessons in the native language for children of immigrants.

Mehrsprachigkeit als Chance 14-15.05 Kassel Harun Osmani

Geboren in der mazedonischen Hauptstadt Skopje

1992 diplomiert an der Universität von Skopje Pädagogische Fakultät Kliment Ohridski 1993 Umzug nach Finnland

Lehrer der Muttersprache Albanisch in Vantaa, Helsinki, Espoo 2000 - 2009 Pädagogischer Koordinator des Muttersprachenunterrichts Region Vantaa, Finnland 


\section{Suomi - Finnland}

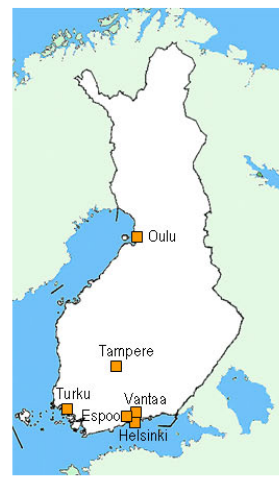

Mitglied der Europäischen Union seit 1995

Fläche: $338145 \mathrm{~km}^{2}$

Einwohnerzahl 5,3 Mio.

(1.1.2009 insgesamt 5326314 )

- Männer 2,6 Mio.(49\%)

- Frauen 2,7 Mio. (51\%)

- Ausländer 133000

Die grössten Städte:

Helsinki, Espoo, Tampere,

Vantaa, Turku, Oulu

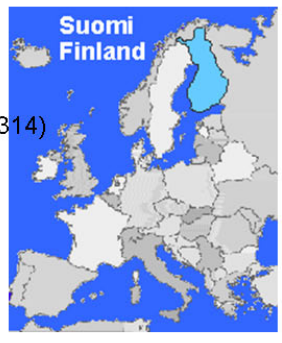

Von Nordfinnland bis Südfinnland ist es $1160 \mathrm{~km}$.

Die breiteste Stelle von Osten bis Westen ist 540

$\mathrm{km}$.

\section{Vantaa}

Viertgrösste Stadt Finnlands

Einwohner (2009)

Fläche, km2 $\sim 195500$

241

Bevölkerungsdichte, Einwohner/km2 793

Steuerprozent 2009

- Wohnstättenfunde die 7000 Jahre alt sind

- Die Name erwähnt in Urkunden erstes Mal im Jahre

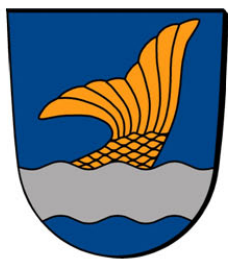

1351

- Das Wappen ist eine Erinnerung an

die Lachse im Fluss Vantaa

- Vantaa ist 200 Jahre älter als Helsinki

- Eine Stadt seit 1974

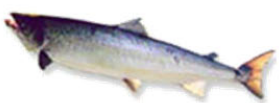


VANTAAN KAUPUNKI

VANDA STAD

\section{Veränderungen im Gebiet Vantaas}

Die Grenzen des Kirchspiels Helsinge 1578

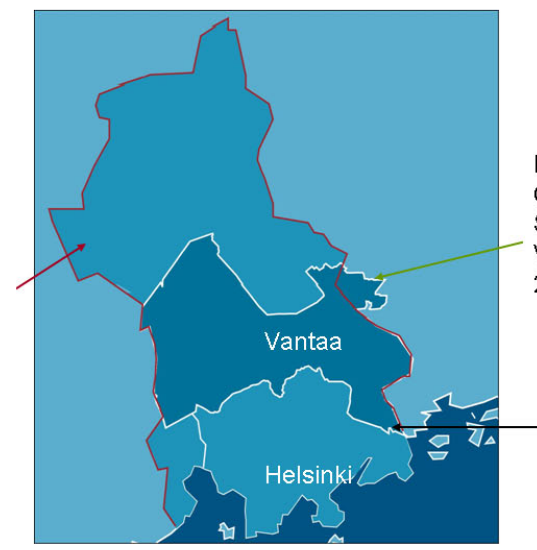

Die

Grenzen der Stadt

Vantaa 2008

Seit Anfang 2009 gehört die südöstliche Ecke zur Stadt Helsinki.

\section{Vantaa ist ein Teil der Region Helsinki}

- Zur Region Helsinki gehört 14 Gemeinden

- Am Anfang 2009 gab es etwa 1,3 Mio. Einwohner im Gebiet

- Städte der Hauptstadtregion Helsinki,

Espoo,

Vantaa

und Kauniainen bilden ein Gebiet der Vetretung des Grossraums Helsinki wo man gemeinschaftlich für ua. Abfallentsorgung und öffentliche Nahverkehr zuständig ist.

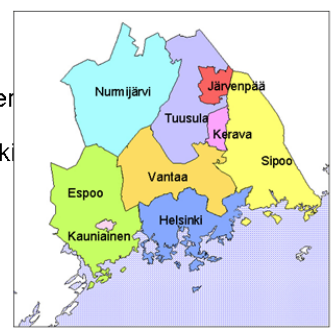

Einwohnerzahlen der Nachbargemeinden im Jahr 2008

$\begin{array}{lc}\text { Helsinki } & \sim 576650 \\ \text { Espoo } & \sim 241550 \\ \text { Vantaa } & \sim 195400 \\ \text { Nurmijärvi } & \sim 39000 \\ \text { Järvenpää } & \sim 38300 \\ \text { Tuusula } & \sim 36400 \\ \text { Kerava } & \sim 33550 \\ \text { Sipoo } & \sim 17850 \\ \text { Kauniainen } & \sim 8550\end{array}$


VANTAAN KAUPUNKI

VANDA STAD

\section{Einfach nach Vantaa zu kommen}

- Ein internationaler Flughafen

- E18 = Ring III

- Hauptbahn

- Staatliche Hauptwege

- Vantaankoski Bahn

- Ringbahn

- Vuosaari Hafen

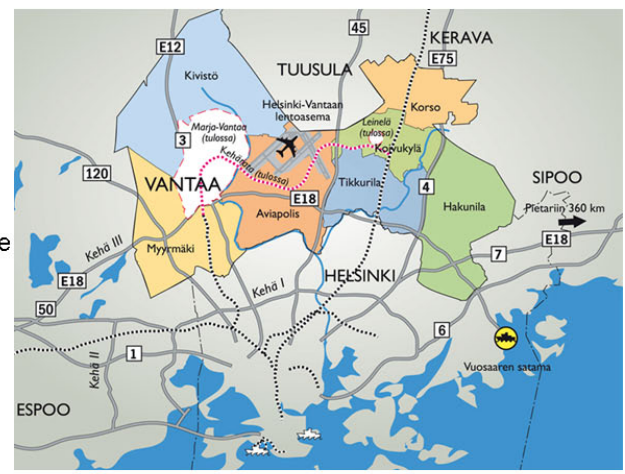

\section{E18 - die nördliche Pulsader}

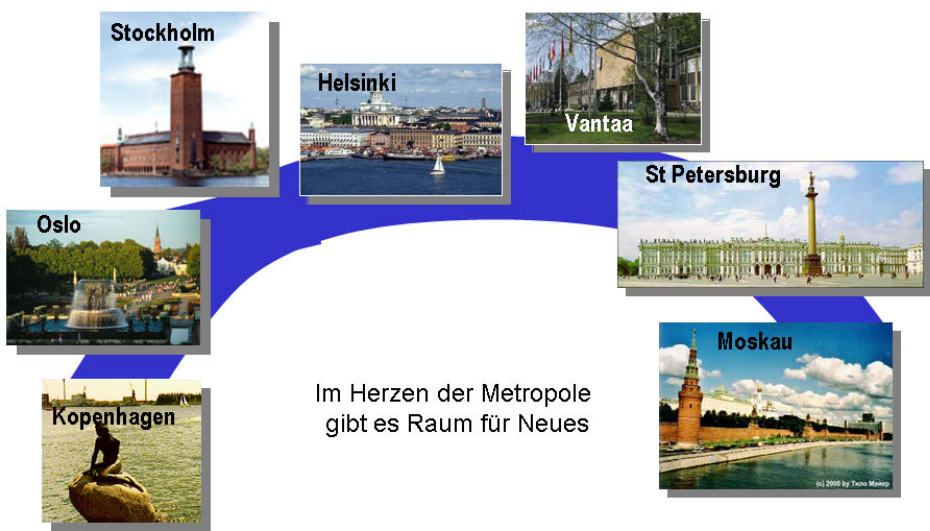




\section{Helsinki-Vantaa Flughafen}

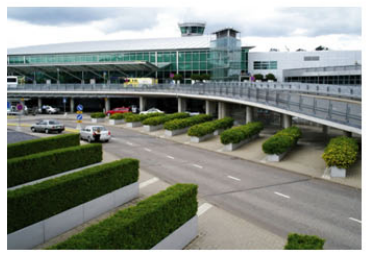

Der Helsinki-Vantaa Flughafen wird von über 13,4 Mio. Passagiere pro Jahr benutzt.

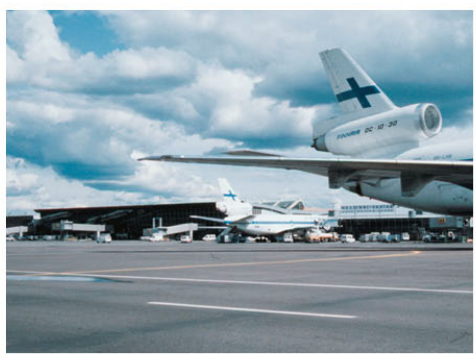

Helsinki-Vantaa gehört seit 1997 zu den besten Flughafen der Welt.

Der Flughafen wurde zu den Olympischen Spielen im 1952 fertiggestellt.

\section{Übernachten in Vantaa}

Reise

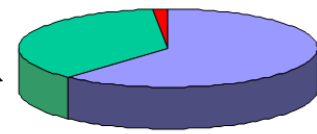

Beruflich $61,6, \%$

Freizeit $36,7 \%$

Anderes $1,7 \%$

- $14 \%$ mehr Übernachtungen als im Jahr 2008.

- In einem Stadtvergleich war Vantaa, gemessen in Übernachtungen, die vierte Stadt nach Helsinki, Tampere und Turku.

- Insgesamte Übernachtungstage: 594 563, einheimische 363130 und ausländische 231 430. Durchsnittliche Übernachtungszeit: 1,3 Tage

- Übernachtungstage/Ausländer, am meisten aus Deutschland, Russland, Schweden und Grossbritannien.

- Es gibt 10 Hotels in Vantaa - Besuchsgrad $62,9 \%$.

- Durchsnittliche Bettkapazität der 1868 Hotelzimmer; 3326 Betten, war 456 grösser als voriges Jahr.

- Durchsnittlicher Preis für Ubernachten ist $73,27 € /$ Nacht. Preis im Jahr vorher war $66,02 € / \mathrm{Nacht}$. 


\section{Anteile der Muttersprachen in Vantaa}

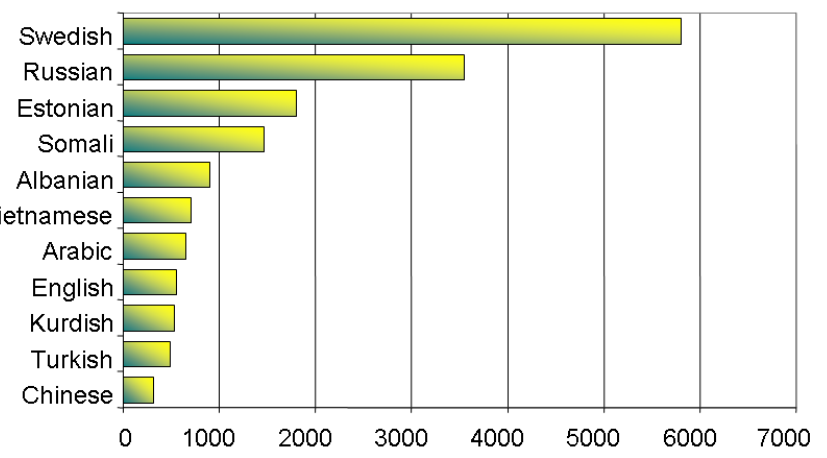

Die gesamte Organisation 1.1.2009

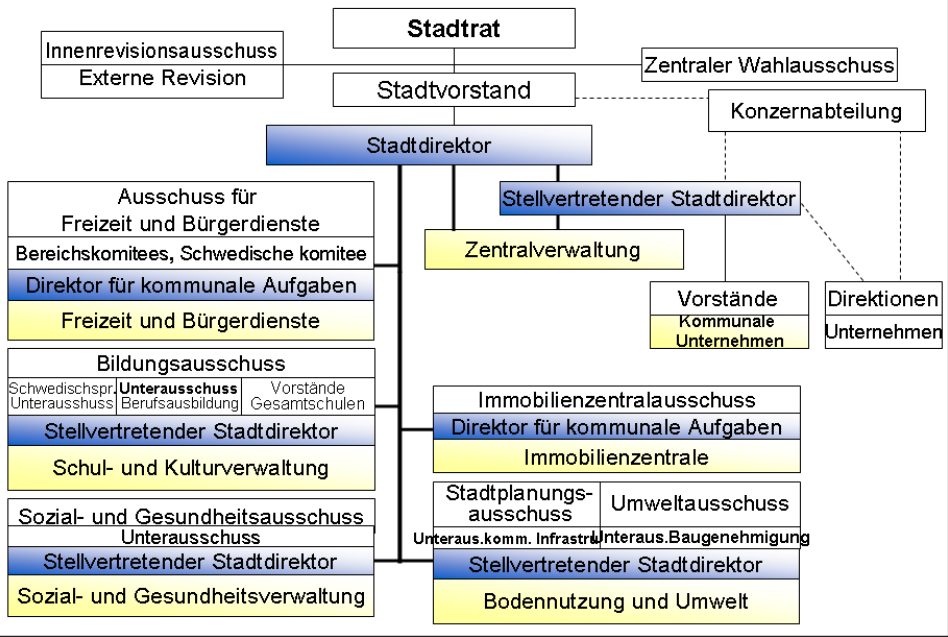




\section{Die Muttersprache in Vantaa}

Das lernen der Muttersprachen in Vantaa, organisieren wir in $\mathbf{3 3}$ verschiedenen Sprachen. Albanisch, Arabisch, Bulgarisch, Dari, Englisch, Spanisch, Persisch, Philipinisch, Hindi, Holländisch,

Isländisch, Italienisch, Japanisch, Kantonesisch, Khmer, Griechisch, Kurdisch, Mazedonisch, Mandarin, Norwegisch, Portugiesisch, Polnisch, Französisch, Roma, Deutsch, Somalisch, Thailändisch, Türkisch, Ungarisch, Urdu, Russisch, Vietnamesisch, Estonisch.

\section{Das Unterrichten der Muttersprache}

Der Unterricht ist freiwillig.

Der Unterricht wird für 2 Stunden in der Woche im Stundenplan organisiert.

Der Unterricht findet nur statt, wenn sich mindestens 5 Schüler anmelden.

Für jede Sprache wird ein Lehrplan erstellt. 


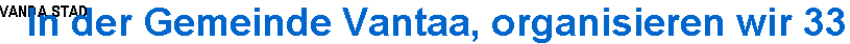
verschiedene Muttersprachen.

Wir haben 62 angestellte Lehrer.

Für diese Gruppen haben wir 4 Koordinatoren die 7 - 8 Sprachen organisieren.

Der Koordinator hat die Aufgabe, mit den Lehrer seiner Gruppe ein monatliches Treffen zu organisieren um die Zusammenarbeit zu verbessern wie bei den Aufgabe:

Lehrplan, Evaluierung, neue Methoden, usw...

$+358405053312$

harun.osmani@vantaa.fi

www.kotikieli.com

www.edu.vantaa. fi

www.edu.vantaa.fi/lansimaki 


\section{KRISTIINA IKONEN}

Schüler mit Migrationshintergrund in finnischen Schulen

Kristiina Ikonen, Leitende Referentin für Schulentwicklung, Finnisches Zentralamt für Unterrichtswesen

Die Präsentation „Schüler mit Migrationshintergrund in finnischen Schulen" von Kristiina Ikonen beschäftigt sich mit dem finnischen Schulsystem mit besonderem Augenmerk auf den Migrantenunterricht.

Kristiina Ikonen's presentation „Schüler mit Migrationshintergrund in finnischen Schulen" deals with the Finnish school system with special focus on the teaching of immigrants.

Schüler mit Migrationshintergrund in finnischen Schulen

Kristiina Ikonen 15.5.2009 


\section{FINNLAND}

-5.2 Millionen Einwohner

-338000 Quadratkilometer Fläche

-17 Einwohner $/ \mathrm{km}^{2}$

-Offizielle Landessprachen: Finnisch 91,5\%, Schwedisch 5,5\%, Samisch in den samischen Gebieten Lapplands 0,03\%

-EU Mitglied seit 1995

\section{DAS FINNISCHE BILDUNGSSYSTEM}

Schematische Darstellung des Bildungssystems

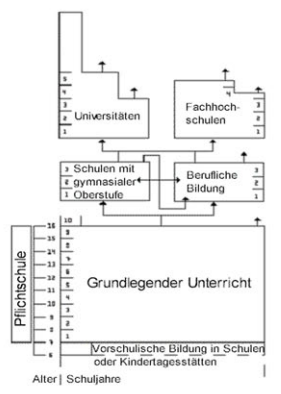




\section{CHARAKTERISTISCHE MERKMALE DES GRUNDLEGENDEN UNTERRICHTS}

- Alle Schüler der Klassenstufen 1 bis 9 in einer Schule für alle

- Nationale Richtlinien für die Lehrpläne (Rahmenlehrplan)

Verantwortlichkeit und Autonomie der Kommunen

- Berufliche Kompetenz der Lehrer

DIE STRUKTUR DES SCHULISCHEN LEHRPLANS IN FINNLAND

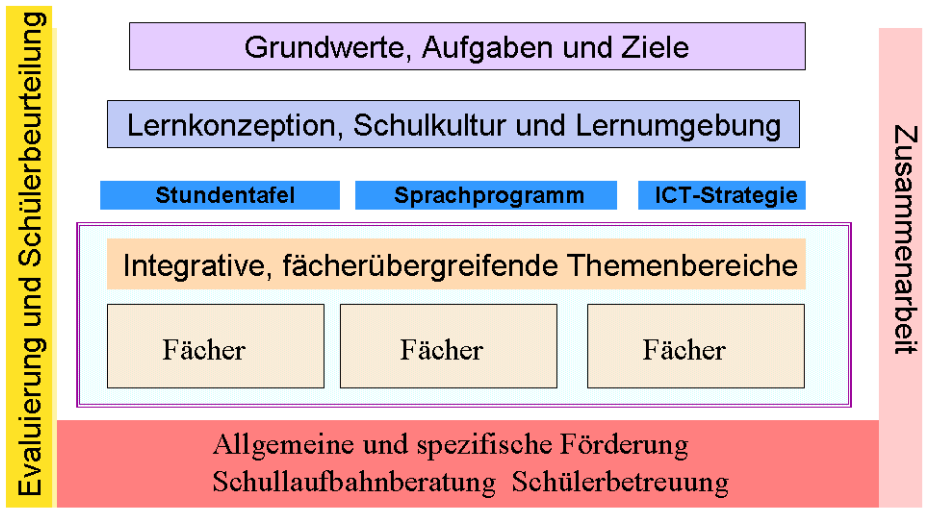

FinNisches zentralam 


\section{ALLGEMEINE FÖRDERUNG DES LERNENS}

ist ein natürlicher und fester Bestandteil des Unterrichts

- Förderunterricht

Schülerbetreuung

- Schullaufbahnberatung

- Zusammenarbeit zwischen Schule und Elternhaus

\section{CHARAKTERISTISCHE MERKMALE DES} MIGRANTENUNTERRICHTS

Berücksichtigung im Rahmenlehrplan

"Der Unterricht soll das Heranwachsen des Schulers zu einem aktiven und ausgeglichenen Mitglied der finnischen und auch der eigenen Sprach- und Kulturgemeinschaft fördern."

- Neben der Sprachförderung spielt das Förder- und Betreuungssystem der Schule eine wichtige Rolle

- Evaluierung von Migrantenschüler 
CHARAKTERISTISCHE MERKMALE DES MIGRANTENUNTERRICHTS

- Vorbereitender Unterricht

- Finnisch/Schwedisch als Zweitsprache

- Muttersprachenunterricht

- Förderung im Fachunterricht

- Zusammenarbeit zwischen Schule und Elternhaus

\section{INFORMATION}

www.oph.fi/english

www.pisa-schuleninfinnland.net

http://virtual.finland.fi/DE/ 


\section{Petra Linderoos}

Das Finnische Schul- und Ausbildungssystem

Petra Linderoos, Sprachenzentrum der Universität Jyväskylä, Finnland

Die Präsentation "Das finnische Schul- und Ausbildungssystem" von Petra Linderoos befasst sich vornehmlich mit dem Fremdsprachenunterricht and finnischen Schulen sowie der Lehrerausbildung an den Universitäten.

Petra Linderoos's presentation „Das finnische Schul- und Ausbildungssystem" deals primarily with the teaching of foreign languages in Finnish schools and the education of teachers at the university.

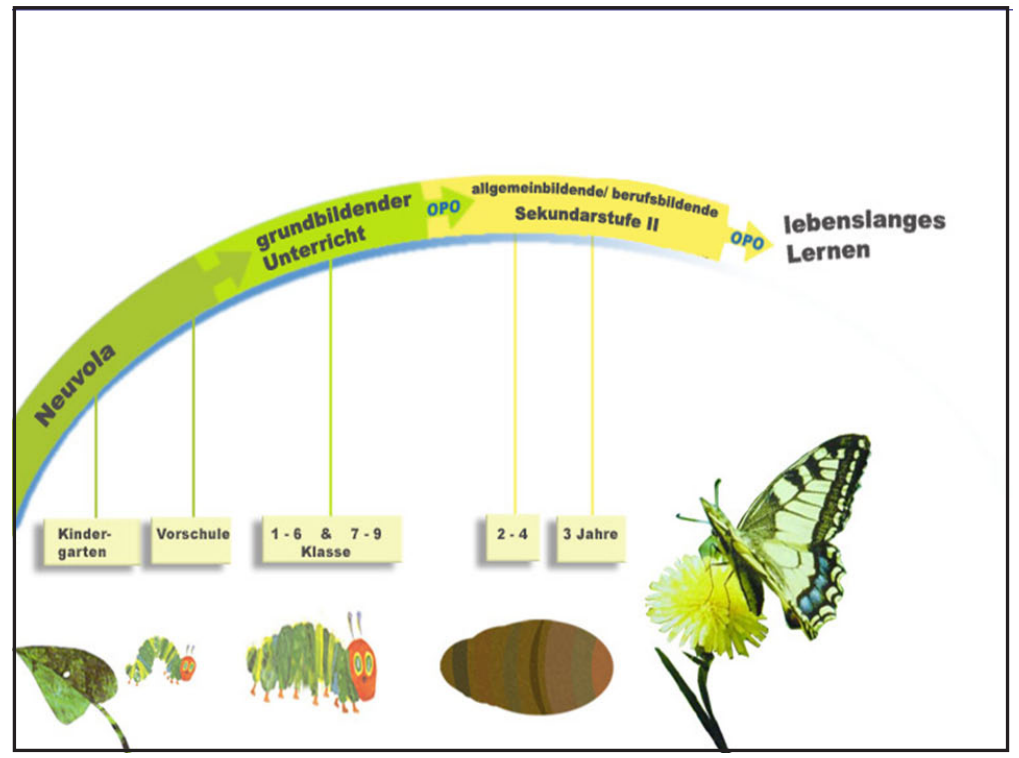




\title{
Lehrpläne für Fremdsprachen. ${ }_{30}$
}

\author{
Zielsetzungen \\ Sprachfertigkeiten, zu erreichende Kulturkompetenz، Ziele: \\ Lernen lernen \\ Zentrale Inhalte \\ Themenfelder, Strukturen und kommunikative Strategie \\ Kriterien für "gute" Kompetenz \\ beschreiben Anforderungen für Sprachenbereiche und \\ Kulturkompetenz \\ GeR als Basis des Unterrichtes und der \\ Evaluierung
}

\section{Europäischer Referenzrahmen als Basis des finnischen Fremdsprachenunterrichts}

A-Sprache ( begonnen in Klassenstufen 1 - 6 ) am Ende der Klassenstufe 6

$\begin{array}{lllll} & \text { Hörverstehen } & \text { Sprechen } & \text { Leseverstehe } & \text { Schreiben } \\ \text { Englisch } & \text { A2.1 } & \text { A1.3 } & \text { n } & \text { A1.3 } \\ \text { andere } & \text { A1.3 } & \text { A1.2 } & \text { A2.1 } & \text { A1.2 } \\ \text { Sprachen } & & & \text { A1.3 } & \end{array}$

A-Sprache ( begonnen in Klassenstufen 1 - 6 ) am Ende der Klassenstufe 9

$\begin{array}{lllll} & \text { Hörverstehen } & \text { Sprechen } & \text { Leseverstehe } & \text { Schreiben } \\ \text { Englisch } & \text { B1.1 } & \text { A2.2 } & \text { n } & \text { A2.2 } \\ \text { andere } & \text { A2.2 } & \text { A2.1 } & \text { B1.1 } & \text { A2.1 } \\ \text { Sprachen } & & & \text { A2.2 } & \end{array}$

B-Sprache ( begonnen in Klassenstufen 8 ) am Ende der Klassenstufe 9

alle Sprachen

Hörverstehen Sprechen

A1.1

$\begin{array}{ll}\text { Leseverstehe } & \text { Schreiben } \\ \text { n } & \text { A1.2 }\end{array}$




\section{Beispiel von Kompetenzstufen}

\section{Leseverstehen A2.1}

versteht einfache Texte mit dem aller gebräuchlichstem

Wortschatz (persönliche Briefe,

Kurzmeldungen, einfache

alltägliche Situationen)

versteht die Hauptgedanken eines Textes und auch einige Einzelheiten in einigen

Textabschnitten. Kann einzelne Informationen finden, vergleichen und gut mit Hilfe des Kontextes einfache Schlussfolgerungen ziehen

liest und versteht auch kurze Textteile

\section{Schreiben A1.3}

kommt schriftlich zurecht in vertrauten, leicht vorhersehbaren Situationen, die sich auf alltägliche Bedürfnisse und Erfahrungen beziehen

Kann einfache Mitteilungen schreiben (einfache Postkarte, persönliche Daten, ein einfaches Diktat)

Kennt die aller gebräuchlichsten Wörter und Ausdrücke, die sich auf das eigene Lebensumfeld oder konkrete Bedürfnisse beziehen. Kann sich mit einigen einfachen Sätzen mitteilen

In der elementaren freien schriftlichen Produktion gibt es alle möglichen Fehler

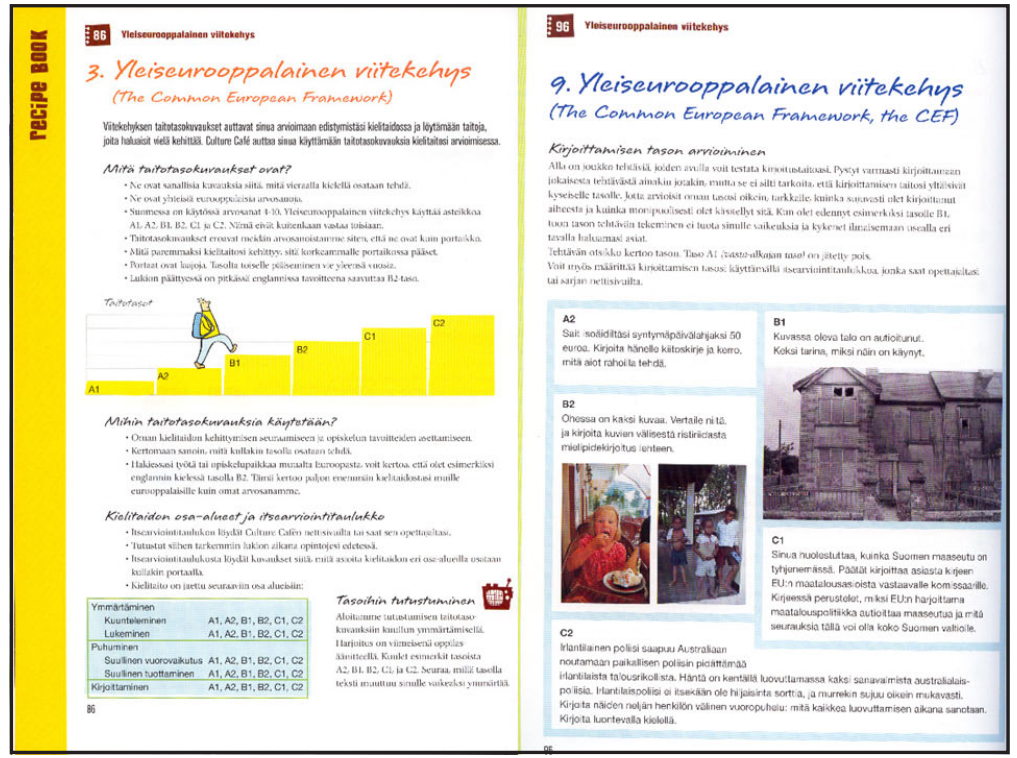




\section{Selbstevaluierung}

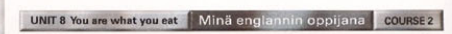

Millainen englannin oppịa olet ollut tână vuonna?

Rasti sopiva vaihtoehto.

- Suullisten tehtavien tekeminen

- Kirjallisten tehtavicn tekeminen

- Keskityminen opiskctavaan asiar

- Kayyós toisia ryhmaan jassenia ja

Valitse joke A tai B.

A Tavoittelen edelleen saman arvosanaa kuin aikaisemmin

(Voit katsoa edellisen arvosanatavoitteesi s. 100.1
Kerro, miksi ansaitset tuon arvosanan.

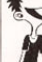

B Arvosanatavoitteeni on muntrunut Uusi tavoitteeni of

\section{FSU in der finnischen Schulen}

obligatorische FS (A1-Sprache) beginnt spätestens in Kl. 3

91, $7 \%$ Englisch

manchmal Deutsch, Schwedisch, Französisch, Russisch etc.

fakultative FS (A2-Sprache) in $\mathrm{KI} .4 / 5$

ca. $27 \%$ Schüler wählen eine A2-Sprache

$7,2 \%$ Deutsch

$8,2 \%$ Englisch

$7.9 \%$ Schwedisch

$2,7 \%$ Französisch 


\section{FSU in der finnischen Schulen (2)}

\section{zweite obligatorische FS (B1-Sprache)} in $\mathrm{Kl} .7$

ca. 90 \% Schwedisch ( / Englisch)

fakultative FS (B2-Sprache) in der Kl. 8 Deutsch: $6,6 \%$ von Schülern

Französisch: 5,4 \%

Russisch: 0,6\%

\section{FSU in der gymnasialen Oberstufe}

obligatorische A1-Sprache

fakultative A2-Sprache

obligatorische B1-Sprache

fakultative B2-Sprache

neue fakultative Sprache, B3-Sprache

Alle lernen mindestens zwei FS 


\section{Lehrerausbildung an Universitåt}

Kindergärtner mind. BA

Klassenlehrer (KI. 1-6)

Fachlehrer (ab KI. 7-9, gymnasiale Oberstufe, Berufs- und Erwachsenenbildung

Sonderpädagogen (Schule + Kita)

Schullauflernberater (OPO)

\section{Bewerbungsverfahren für einen Studienplatz}

- Zeugnisse

- schriftliche Aufnahmeprüfung (2x)

- zweistufige mündliche Aufnahmeprüfung

Kommunikationsfähigkeit

Motivation zur Lehrerausbildung realistisches Bild vom Lehrerberuf 


\section{Aufbau des eines Lehrerstudiums}

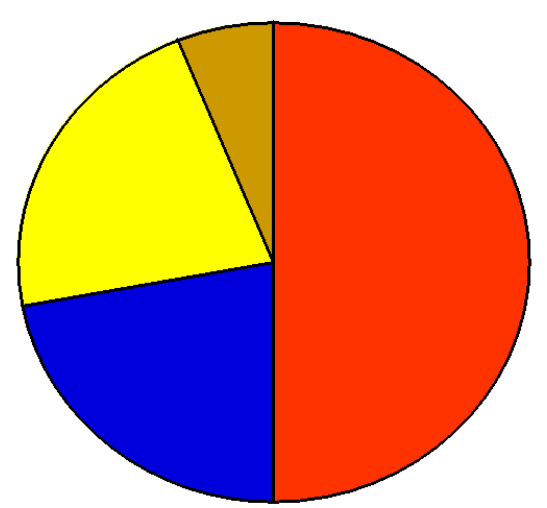

Hauptfach

Nebenfach

Pädagogik

Kommunikationskurse

\section{Studium für Klassenlehrer (k1.1-6)}

\section{SP/ 5 Jahren}

\section{Hauptfach Erziehungswissenschaften}

25 Grundstudium

35 Fachstudium

80 vertiefendes Studium

umfasst Proseminar, Magisterarbeit und Praktika in den drei Stufen

60 alle Fächer der KI. 1-6/Schwerpunkt: Didaktik

Finnisch/Schwedisch Muttersprache, Mathe, Geschichte, Musik, Umweltlehre, Gesundheitslehre, Kunsterziehung, Sport, Religion, Chemie, Handarbeit, Physik,

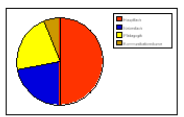




\section{5 ein / zwei Nebenfächer}

Wahl der Nebenfächer frei z.B.:

Sport, Musik, frühkindliche Erziehung, etc.,

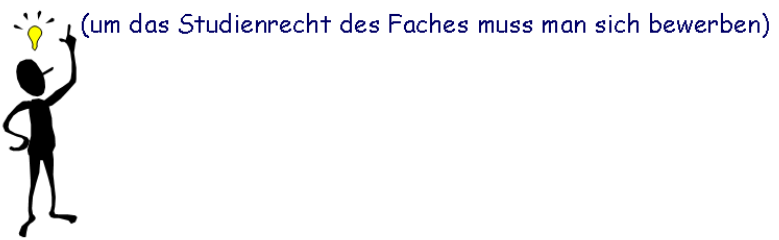

Arbeit in Hausgruppen

\section{Kommunikationskurse (sprachenzentrum)}

Einführung ins Studium, Erstellung eines individuellen Lernplanes (HOPS)

Einführung ins wissenschaftliche Arbeiten

Informationstechnologie/ -beschaffung

Schwedisch/Finnisch als Muttersprache und Interaktionskompetenz

2. Landessprache

Fremdsprache / Englisch 


\section{FACHLEHRERSTUDIUM}

am Beispiel Deutsche Sprache und Kultur

Magisterstudium inkl. Lehrerausbildung

(:) fünfjähriges Studium /300 SP

160 Hauptfachstudium

65 Nebenfach

60 Pädagogik

15 Sprach- und Kommunikationskurs
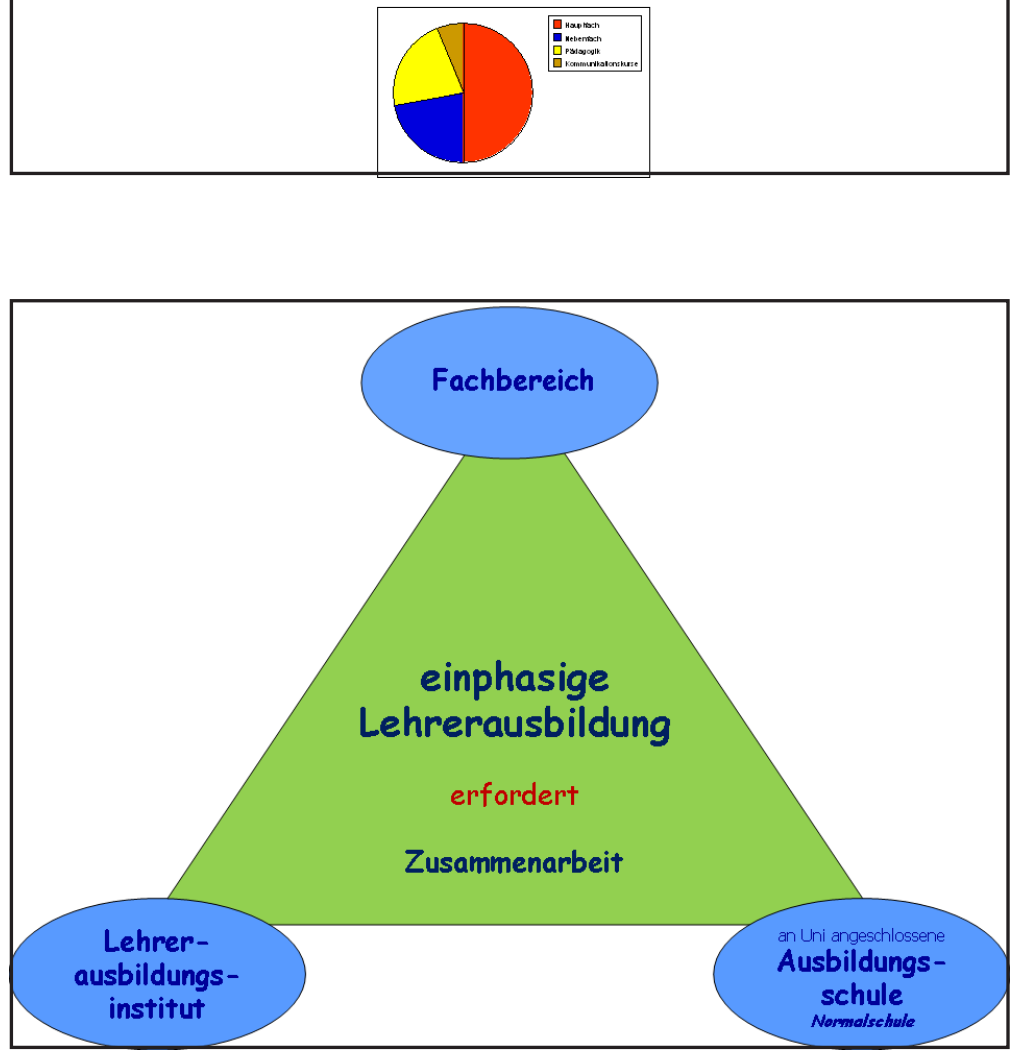


\section{Betreute Praktika an der Ausbildungsschule}

1.

Begegnung und bekannt werden mit der Arbeit eines Lehrers auf der Basis wissenschaftlicher Forschung (4 SP)

Ziel: u.a.: Forschung der eigenen, subjektiven Gewohnheiten, Ereignisse in der Schule wahrzunehmen und zu interpretieren

2.

Planung als Basis des Unterrichtens und des Lernens (8 SP)

Ziel: u.a.: Kompetenzerwerb bei der Planung des Unterrichts, der Lernsituationen, Umsetzung und Bewertung, Begegnung mit der Vielfältigkeit der Schüler

3.

Fokus auf ein spezielles Gebiet des Lehrerseins (10 SP)
z.B.: a. Unterrichten der Nebenfächer
b. Praktikum in jahrgangsstufenübergreifendem Unterricht und Praktikum in einer Schule eigener Wahl

Ziel u.a.: Zusammenarbeit und das schulische Umfeld kennen lernen

\section{4. \\ Forschender, experimentierender und sein eigenes Denken und das des Schülers entwickelnder Lehrer (6 SP) \\ Ziele u.a.: Berufliche Autonomie, Gesamtheit des Schulbetriebs kennen lernen, Zusammenarbeit mit den Kollegen lernen, Arbeit am Curriculum, Projekte etc.}




\section{Pädagogischer}

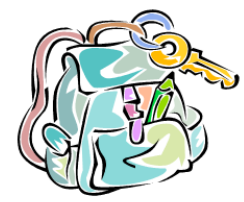

Vertrauen in Lernmöglichkeiten aller Schüler

jeder Schüler hat irgendwelche Fähigkeiten

Kompetenzen entdecken, fördern, nicht bewerten

offener, respektvoller Umgang durch eine dialogische Gesprächskultur

positive Lernatmosphäre

sich gegenseitig wahr + ernst nehmen

Lernprozesse erfordern Geduld und Ausdauer

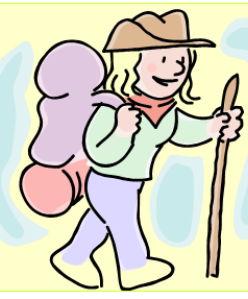




\section{ELISABETH GeSSNER \\ Horst Paul Kuhley}

Schule - Sprache - Migration

Elisabeth Gessner, Pädagogische Mitarbeiterin an der Universität Kassel.

Horst Paul Kuhley, Pädagogischer Mitarbeiter an der Universität Kassel.

Die zugehörige Präsentation kann im Internet unter http://www.uni-kassel.de/fb1/lesenundschreiben/ abgerufen werden.

Neveda, die türkischstämmige Deutschlehrerin in der Brennpunktschule, hat für ihre multikulturell zusammengesetzte Klasse eine Unterrichtseinheit vorbereitet, in der es um Märchen geht. „Erzählt doch mal ein Märchen aus Eurem Heimatland" fordert sie ihre Klasse auf. Betretenes Schweigen folgt, den Kindern wollen keine Märchen aus ihren Heimatländern einfallen. Die intensive Nachfrage der Lehrerin fördert zu Tage, dass zu Hause einfach keine Märchen mehr erzählt werden. Von wem denn auch? Die Großmutter lebt in der Türkei und die Eltern sind selbst schon so lange in Deutschland, dass sie keine Märchen aus ihrer Kindheit in der Heimatsprache erzählen könnten. So muss die Kollegin die Idee der Unterrichtseinheit „Märchen aus meinem Heimatland“ auf den Kopf stellen und selbst nach Märchen suchen, die sie den Kindern mitbringen kann

Abhilfe schaffen könnten entsprechende ein- oder zweisprachige Unterrichtsmaterialien für „Deutsch als Zweitsprache“(DAZ). Hier wiederum stellt sich aber das Problem, dass die türkischen Kinder 
die ihnen in solchen Unterrichtseinheiten zugedachte Funktion gar nicht erfüllen können: „SchülerInnen mit der Erstsprache türkisch übernehmen im Unterricht ExpertInnenfunktion: Sie können etwas sagen zur Funktion und Tradition der Märchen in ihrer Heimat (...)“(Huth, 1994). Dies können sie, wie gesagt, mitnichten.

Welche Förderung wollen Kinder und Jugendliche mit Migrationshintergrund, wenn man sie selbst fragt? Die Ergebnisse des zweiten ,Jugendintegrationsgipfels' im Bundeskanzleramt wurden von der zuständigen Staatsministerin und Integrationsbeauftragten der Bundesregierung, Maria Böhmer, in ihrer Presseerklärung so zusammengefasst: „(...)Die junge Generation aus Zuwandererfamilien betrachtet Deutschland als ihre Heimat. (...) Sie wollen dazu gehören, wollen die Zukunft unseres Landes mitgestalten (...)“. Und zu den Forderungen der Jugendlichen gehört zum Beispiel: „Das Beherrschen der deutschen Sprachen ist Voraussetzung/Bedingung “ und „Mehr Berufsorientierung in der Schulzeit.“ (Presse- und Informationsamt der Bundesregierung, 2008)

,Politik und Wirtschaft' in einer 10. Klasse, kooperative Gesamtschule, 29 Schülerinnen und Schüler. Manuel, Student im Schulpraktikum, hat sich als Thema die ,Soziale Marktwirtschaft' vorgenommen. Das Thema wird zeitgleich in allen 10. Klassen an dieser Schule behandelt. Der, Ausländeranteil' bei den Schülern liegt bei ca. 60 Prozent, in dieser Realschulklasse ist er sogar noch höher.

Der Einstieg in die Stunde mit einer Karikatur wirkt motivierend. Danach sollen aus einem typischen Lehrbuchtext abstrakte ,Merkmale der Marktwirtschaft" herausgesucht werden (Konsum- und Gewerbefreiheit, Freiheit der Berufswahl etc.). Die Auflistung an der Tafel gestaltet sich zäh. Es wird mehr als deutlich, dass die Begriffe zwar mit Mühe im Text identifiziert werden können, aber zunächst nicht, verstanden ', d. h. mit Anschauung gefüllt werden. 
Dies gelingt schließlich mit ein paar einfachen Fragen, die auf das Vorwissen und die persönliche Situation der Schüler abzielen: „Kann sich jeder von euch seinen zukünftigen Beruf frei aussuchen?“ „Habt Ihr euch schon einmal beworben oder habt Ihr das bei Freuden miterlebt?" Im lebhaften Diskussionsprozess über die eigenen Berufsperspektiven füllt sich der Begriff der, freien Berufswahl' für jeden Einzelnen mit konkretem Inhalt und wird damit für reflexive Überlegungen zugänglich. Das Gleiche geschieht mit der, Gewerbefreiheit', ausgelöst durch die Schülerfrage: Was muss ich lernen, wenn ich später einen Elektronikmarkt eröffnen möchte? Natürlich lässt sich diese Frage nicht sofort hinreichend beantworten. Es zeichnen sich aber Umrisse eines kleinen, handlungsorientierten Planspiels ab, mit dem man den Unterricht in den Folgestunden fortführen kann. Die Erwartungen der Schüler sind realistisch und zweckorientiert, man könnte auch sagen: affirmativ. Es wird deutlich, dass sie in dieser Gesellschaft ankommen, hier erfolgreich sein wollen. Nähme man dieses Bedürfnis nach sehr weltbezogenem Kompetenzerwerb nicht ernst, würde man ihnen etwas schuldig bleiben.

\section{Interkulturelle Integrationskonzepte in der Kritik}

Solche sehr pragmatisch auf das ,Ankommen“ in unserer Gesellschaft ausgerichtete Wünsche wurden von der interkulturellen Didaktik bisher zu wenig erfüllt. Viele Maßnahmen und Konzepte orientierten sich stark an den ,Herkunftskulturen', wobei zumeist auch eine mehr oder weniger explizite ,Rückkehr-Option' mitschwang. Dies hat unserer Ansicht nach dazu beigetragen, dass viele der zahllosen „Klimmzüge gegen die doppelte Halbsprache“ (Frankfurter Rundschau 21.12.2007) bei Jugendlichen mit Migrationshintergrund keinen oder nur mäßigen Erfolg hatten und die sprachabhängigen Integrationsprobleme sogar gewachsen sind, wie die PISA Studie feststellte (Baumert et al. 2001).

Das lange Zeit favorisierte Konzept des Muttersprachlichen Unterrichts beruhte auf der Annahme, dass man eine zweite Sprache nur 
dann gut lernen kann, wenn man vorher die Muttersprache ausreichend beherrscht - eine plausible, wenn auch empirisch bisher nicht belegte Hypothese. Es gibt viele biographische Auskünfte von Migranten, die auch die Annahme des Gegenteils nahe legen. Explizites Ziel für den muttersprachlichen Unterricht war zum Beispiel in Hessen nach Aussage des ,Migrationsreports' „,... die Möglichkeit der Wiedereingliederung in die Schule des Herkunftslandes offen (zu) halten" (Tischler, 2002). Abgesehen davon, dass die Konzentration nur auf die großen Immigrantengruppen von vornherein ungleiche Bildungschancen innerhalb der betroffenen Schülergruppe bewirkte, war das Angebot faktisch nie flächendeckend und der Unterricht fand außerhalb der regulären Unterrichtszeit statt. Dies hatte zur Folge, dass es keine Verzahnung zwischen dem muttersprachlichen und dem übrigen Unterricht gab und oft keine Kommunikation zwischen den Lehrpersonen. Ein erkennbar positiver Effekt des muttersprachlichen Unterrichts auf die Leistungen in Deutsch war nur schwerlich auszumachen.

In anderer Weise trifft die Kritik auch auf zahlreiche Konzepte und Materialien für ,Deutsch als Zweitsprache (DaZ) ${ }^{`}$ zu, wie zum Beispiel auf den sehr verbreiteten Ansatz von Neuner (Neuner, 1995). Sehr vereinfacht gesagt ist der Ausgangspunkt der DaZ-Konzeption die Erkenntnis, dass Deutsch für Schüler/innen mit Migrationshintergrund wie eine Fremdsprache unterrichtet werden muss. Die entsprechenden Praxiskonzepte greifen also auf Erkenntnisse der Fremdsprachendidaktik zurück, verbinden diese allerdings mit einer sehr starken inhaltlichen Ausrichtung des Materials auf die Kultur der Herkunftsländer. In der konkreten Umsetzung bedeutete das eine besondere Beschäftigung mit Gebräuchen, Literatur und Märchen der Herkunftsländer und mit Jugendbüchern, die Probleme der Migration thematisieren.

Der Sprachunterricht wurde allerdings durch diesen interkulturellen Anspruch oft heillos überfrachtet und viele Kollegen fühlten sich 
überfordert. Gerade bei sehr engagierten Lehrpersonen hat das Resignation ausgelöst und dazu geführt, dass dieses idealistische Konzept in die Defensive geriet. Sehr kritisch betrachtet, kann man es ebenfalls als einen in das Positive gewendeten Versuch des Erhalts von ,Rückkehr-Optionen' interpretieren.

Als problematisch erwiesen hat sich auch ist die Verabsolutierung des didaktischen Prinzips der Binnendifferenzierung. Neben dem zusätzlichen Angebot des muttersprachlichen Unterrichts sollte es nach dieser Philosophie möglichst wenige oder gar keine äußerlich differenzierenden Fördermaßnahmen geben, da die äußere Differenzierung im Kontext des gegliederten Schulsystems unter dem Generalverdacht der Selektion und Diskriminierung stand.

Nahezu überall im europäischen Ausland - zum Beispiel auch in Finnland - werden Fragen der Differenzierung allerdings pragmatischer diskutiert. Äußere und innere Differenzierungsmaßnahmen werden dort zu einem flexiblen System verbunden, welches den individuellen Bedürfnissen der Lerner optimal gerecht wird. Keinem Kind mit unzureichenden Sprachkenntnissen nützt es schließlich, wenn es im Biologie-, Mathematik- oder Deutschunterricht herumsitzt ohne etwas zu verstehen.

Eine offenbar erfolgreiche Reaktion auf den ,PISA-Schock' war dagegen die Einführung von sog. Vorlaufkursen in zahlreichen Bundesländern. Beim vorgezogenen Anmeldetermin für alle zukünftigen Grundschüler werden deren Sprachkenntnisse verpflichtend überprüft, unabhängig von ihrer Nationalität und Herkunft. Werden dabei unzureichende Deutschkenntnisse festgestellt, sollen die Kinder mehrmonatige Deutschkurse besuchen, die in Zusammenarbeit von Schulen und Kindergärten wohnortnah organisiert werden.

Der Besuch dieser , Vorlaufkurse ' wird sehr gut angenommen, da die Kinder vom Schulbesuch zurückgestellt werden können, wenn ihre sprachlichen Defizite nicht aufgearbeitet wurden. 
In der Praxis hat sich gezeigt, dass die von einigen Pädagogen befürchtete Diskriminierung nicht eingetreten ist und die Akzeptanz der Vorlaufkurse bei den ausländischen Eltern von Beginn an sehr hoch war, auch ist die tatsächliche Rückstellungsquote außerordentlich gering. Wichtig erscheint uns dabei, dass diese Kurse zwar überwiegend Kindern mit Migrationshintergrund zugute kommen, grundsätzlich aber auch für deutsche Kinder mit Sprachdefiziten offen sind und (in allerdings wesentlich geringerer Zahl) auch von diesen besucht werden. Der pädagogische und didaktische Ansatz dieser Kurse stellt im Unterschied zu vielen anderen Initiativen nicht die ,Herkunft ' in den Mittelpunkt, sondern orientiert sich am systematischen Erlernen von sprachlichen Standards, die im deutschen Schulsystem vorausgesetzt werden und je nach sozialem Milieu auch von Muttersprachlern nicht immer erreicht werden.

Sieht man von dem zuletzt skizzierten Beispiel der Vorlaufkurse ab, ist ein Großteil der bisherigen Konzepte unserer Ansicht nach de facto zu stark auf , herkunftsorientierte' Eltern, Kinder und Jugendlichen mit Migrationshintergrund zugeschnitten. Die im Folgenden dargestellte Schweizer Untersuchung lässt aber vermuten, dass die Gruppe der SchülerInnen und Schüler mit Migrationshintergrund, die sich explizit eine ,Rückkehr-Option' offen halten möchte, in der Schule zahlenmäßig nicht die größte ist.

\section{Sozialstatus und kulturelle Orientierung als entscheidender Faktor}

Die typischen ,Schüler/innen mit Migrationshintergrund' gibt es nicht. Kultur und Sprache der Herkunftsländer, vor allem aber der Sozialstatus in der deutschen Gesellschaft können - neben anderen Faktoren - recht unterschiedliche Formen der Förderung nahe legen. Hilfreich erscheinen uns in diesem Zusammenhang einige aktuelle Erkenntnisse der Medienpädagogik, z. B. der sehr lesenswerte Aufsatz von Ben Bachmair (Bachmair, 2007) 


\begin{tabular}{|c|c|c|c|c|}
\hline \multicolumn{5}{|c|}{ Kulturelle Orientierung } \\
\hline & $\begin{array}{l}\text { Schweiz- } \\
\text { Orien- } \\
\text { tierte }\end{array}$ & Dualisten & $\begin{array}{l}\text { Her- } \\
\text { kunfts- } \\
\text { Orien- } \\
\text { tierte }\end{array}$ & $\begin{array}{l}\text { Ungebun- } \\
\text { dene }\end{array}$ \\
\hline $\begin{array}{l}\text { Ex-Jugosla- } \\
\text { wien Kinder }\end{array}$ & 41 & 27 & 25 & 7 \\
\hline $\begin{array}{l}\text { Ex-Jugosla- } \\
\text { wien Eltern }\end{array}$ & 13 & 35 & 45 & 2 \\
\hline Italien, Kinder & 41 & 23 & 29 & 7 \\
\hline Italien, Eltern & 20 & 30 & 48 & 4 \\
\hline Türkei, Kinder & 41 & 28 & 24 & 7 \\
\hline Türkei, Eltern & 10 & 31 & 57 & 2 \\
\hline
\end{tabular}

zum ,Leserisiko und der Medienumgebung von Migrantenkindern ‘ sowie die dort zitierte Studie von Bucher/Bonfadelli zum Medienverhalten von Schweizer Jugendlichen. Die Schweizer Forscher untersuchten neben sozialen Faktoren vor allem auch die , kulturelle Orientierung' der befragten Jugendlichen mit Migrationshintergrund, d. h. das Verhältnis zur Herkunftskultur und zur Schweizer Gesellschaft. Sie beschreiben dabei vier Gruppen (, Schweiz-Orientierte ' / ,Dualisten “/,Herkunfts-Orientierte' und ,Ungebundene'), die sich nicht nur in ihren Werturteilen und Gewohnheiten stark unterscheiden, sondern auf die auch mit jeweils sehr unterschiedliche Formen der Förderung zugegangen werden muss.

Diese Beschreibung erscheint uns leicht auf deutsche Verhältnisse übertragbar, da sie kulturelle Grundorientierungen von Jugendlichen fragt und diese als Ausgangspunkt nimmt, um nach unterrichtsrelevanten Konsequenzen zu fragen. Deutsche Befunde legen ähnliche Schlussfolgerungen nahe. 
So sagt Christian Alt vom ,Deutschen Jugendinstitut' im DJI Bulletin 76 (2006): „Wer aus einem niedrigen Milieu stammt - gleichgültig ob mit oder ohne Migrationshintergrund - wird stets die gleichen Probleme im Bildungsbereich haben."

Aus den beiden oben zitierten Feststellungen lassen sich Konturen einer modifizierten ,Didaktik der interkulturellen Bildung' ableiten: Interkulturelle Bildung sollte sich von der Fiktion eines homogenen Status ,Migration' verabschieden und sich den konkreten Bedürfnislagen der verschiedenen und Milieus zuwenden. Entscheidende Faktoren für Förderkonzepte sind dann die unterschiedliche soziale Situation von Kindern (seien sie Migranten oder seien sie Deutsche) und ihre kulturelle Orientierung. Dies erfordert selbstverständlich auch eine Veränderung der politischen Rahmensetzungen für Förderkonzepte, die sich bislang viel zu sehr an der Herkunftsfrage orientieren.

Wir stützen uns bei dieser Forderung nach einer neuen ,Didaktik der interkulturellen Bildung' auf einen Bildungsbegriff, wie ihn Eckhard Klieme (2005) im Zusammenhang mit der Entwicklung der bundesdeutschen Bildungsstandards formuliert hat: „Bildung ist (...) ein Prozess, in dem sich Menschen die sie umgebende Kultur, das System von Normen und Regeln, Wissen und Fertigkeiten erschlieBen und aneignen". Sehr wichtig erscheint uns dabei, dass die Forderung nach ,Aneignung und Erschließen der kulturellen Umgebung' keinesfalls als rezeptive Einbahnstraße zu verstehen ist, sondern als aktiver Prozess, der auch die Umgebung immer wieder kritisch hinterfragt und den Schülern eine eigenständige Adaption und Veränderung der Umgebung erlaubt.

\section{,Bildungsstandards' gegen ,Interkulturelles Lernen'?}

Kritiker befürchten, dass die oben erwähnten Bildungsstandards den vorhandenen Selektionsdruck verstärken werden. Die in diesem 
Kontext entwickelten ,neuen Aufgabenformate' verlangen in viel höherem Maße als frühere Prüfungsaufgaben die Aktivierung von Vor- und ,Weltwissen', das heißt Formen von sprachlichem Handeln und sozialen Einsichten, die wesentlich stärker als bisher Lebensweltbezüge im Unterrichts voraussetzen.

Wer die in den Standards vorgegebenen Aufgaben zum Beispiel für das Fach Mathematik ansieht, wird feststellen, dass für das erfolgreiche Absolvieren der Hauptschulabschlussprüfung in Mathematik auch juristische Grundkenntnisse - zum Beispiel im Verbraucherrecht - nötig sind. In den entsprechenden Lehrplänen der Bundesländer für das Fach Mathematik fehlen jedoch bislang Unterrichtsvorschläge, die zum Erwerb dieser Kenntnisse führen. Es ist eine primäre Aufgabe der Schule, solche didaktischen Lücken offensiv zu schließen.

Die bisher von manchen Kolleginnen und Kollegen in den Abschlussklassen praktizierte Methode des ,teaching to the test" für die Bewältigung von derartigen Abschlussprüfungen wird die Kompetenzen zur Bewältigung von Alltagssituationen kaum nachhaltig verbessern. Statt dieser, subversiven' Methode, mit unzureichend vorbereiteten Neuerungen im Bildungsbereich fertig zu werden, schlagen wir einen curricularen Ansatz vor, bei dem im Kollegium einer Schule gemeinsam ein geeigneter Text- und Aufgabenfundus aufgebaut und das Zusammenwirken verschiedener Fächer systematisch verankert wird. Wie man ein solches Schulcurriculum aufbauen könnte, haben wir an anderer Stelle am Beispiel von ,Beruflichkeit' als organisierender Leitlinie gezeigt. (Gessner/Kuhley 2006), Diesen Ansatz kann man mit Hinblick auf Schüler/innen mit Migrationshintergrund noch weiter ausdifferenzieren.

So kann für Kinder und Jugendliche mit sprachlichem Förderbedarf - auch ausgehend von ihrer Mediennutzung - systematisch an der Erweiterung von Kompetenzen für den Schul- und späteren Berufs- 
erfolg gearbeitet werden, die eine gleichberechtigte schulische und gesellschaftliche Teilhabe erst ermöglichen. Dabei sind offene Formate, Problemorientierung und Handlungsbezug unserer Erfahrung nach motivierend und haben darüber hinaus noch den Charme, dass sie auf das , wirkliche Leben' vorbereiten.

Schüler mit größeren Sprach- oder Lernproblemen werden allerdings durch allzu offene Unterrichtsarrangements überfordert und können daher weniger mit ihnen anfangen als sprachgewandte, gute Lerner, wie zum Beispiel auch Untersuchungen von Andrea Bertschi-Kaufmann (2006) gezeigt haben. Zur Unterstützung für solche Schüler empfehlen wir deshalb eine stärkere Strukturierung des Lernprozesses, mehr Hilfestellung, mehr Training und mehr Systematik als für die leistungsstarken Schüler. Eine Kombination von offenen Aufgabenformaten mit systematischem Training scheint sich insgesamt zu bewähren, gerade auch in der Sprachförderung für Kinder und Jugendliche mit Migrationshintergrund.

\section{Mentorenprogramme mit erfolgreichen Migranten aufbauen}

Auf einen vielversprechenden und anscheinend effektiven Weg für die Organisation zusätzlicher Förderung verweisen Mentorenprogramme ,mit Migrationshintergrund'. Solchen Programmen ist gemeinsam, dass die Mentorenrolle von erfolgreichen Migrantinnen und Migranten übernommen wird, die ihre Erfahrungen authentisch weitergeben können.

Exemplarisch soll hier das Hamburger Projekt ,Junge Vorbilder' skizziert werden. Dieses Projekt richtet sich besonders an Schüler/ innen der 9. bis 11. Klasse, die einen guten Schulabschluss anstreben oder in die gymnasiale Oberstufe wechseln möchten. Sie werden dabei von Studierenden der Universität Hamburg in Einzelförderung oder Kleingruppen fachlich und sozial-emotional unterstützt. Diese Unterstützung kann Sprachförderung oder klassische Nachhilfe bedeuten, vor allem aber soll sie Orientierung und Moti 
vation vermitteln. Die Mentoren fungieren dabei als ,Erfahrungsexperten', die vorhandene Schwierigkeiten aus eigener Erfahrung kennen, dann aber Lösungswege gefunden haben und deshalb ,Strategien und Tipps für das erfolgreiche Bestehen im Schulsystem vermitteln können'. So hat man einige der Kurse, die ursprünglich in den Stadtteilschulen angeboten wurden, inzwischen in die Universität verlegt - mit anscheinend durchschlagendem Erfolg: Die Schüler/innen ,müssen' nun nicht mehr nachmittags in ihrer Schule ,nachsitzen', sondern sie ,dürfen' in die Universität. Fördermaßnahmen werden dadurch zum angesagten Prestigeobjekt (Quelle: http:// www.verikom.de/junge_vorbilder.htm).

\section{Netzwerke für den Förderunterricht knüpfen}

Sicher ist: Die Schule allein wird nicht alle Probleme der sprachlichen Integration lösen können, sondern sie kann und sollte auf die Hilfe der Gesellschaft setzen und sich beispielsweise mit Stadtteilgruppen, türkischen Gemeinden, orthodoxen Serben und vielen anderen Gruppen in einem kommunikativen Netzwerk verankern, das auf die gemeinsame Zielsetzung ausgerichtet ist: Ankommen in Deutschland.

Wer sich im Unterricht mit benachteiligten Schülerinnen und Schülern auf die Verbesserung ihrer Berufsperspektiven und Lebenschancen konzentriert, wird vielleicht nicht so intensiv auf die vielen Dinge eingehen können, die ohne Frage an der deutschen Gesellschaft zu kritisieren sind. Auch wird man sich, statt über ,Bildungsstandards' und ,neue Aufgabenkultur' zu klagen, mehr mit der Frage beschäftigen, wie man Unterricht so aufbauen kann, dass die fehlenden Kompetenzen systematisch erworben werden können. Und vielleicht muss man auch auf manche liebgewordene Jugendbuch-Lektüre zugunsten einer Lektion in Verbraucherrecht verzichten. Wir halten das für vertretbar. 


\section{Literatur:}

Alt, Christian (2006). Milieu oder Migration - Was zählt mehr? DJI Bulletin 76 3/2006 S. 11

Bachmair, B. (2007). Migrantenkinder, ihr Leserisiko und ihre Medienumgebung, in: Aus Politik und Zeitgeschehen, Beilage zur Wochenzeitung Das Parlament, 28/2007, S. 32-38

Baumert et al.: (Hrsg.)(2001). PISA 2000, Opladen 2001, S. 401 Bertschi-Kaufmann, A. / Schneider, H. (2006). Entwicklung von Lesefähigkeit: Maßnahmen - Messungen - Effekte. Ergebnisse und Konsequenzen aus dem Forschungsprojekt ,Lese- und Schreibkompetenzen fördern. Schweizerische Zeitschrift für Bildungswissenschaften 28 (3)

Bucher, P./Bonfadelli, H. (2007). Jugendliche mit und ohne

Migrationshintergrund. Gemeinsamkeiten und Unterschiede im Umgang mit Medien, in: Mikos, L. u. a (Hrsg), Mediennutzung. Identität und Identifikationen. Weinheim-München 2007

Gessner, E. / Kuhley, H. (2006). Berufsorientiert lesen und schreiben. Deutschmagazin 3/06, München: Oldenbourg Vlg. S. 27-34

Huth, Manfred Hrsg. (1994). Deutsch als Fremdsprache - Deutsch als Zweitsprache. Das schnelle AOL-Nachschlagewerk. Hits für den Unterricht, Band 4. Lichtenau / Baltmannsweiler: AOL-Verlag / Schneider Verlag Hohengehren, S. 136ff. - Ergänzend aus der Perspektive der Zweisprachigkeit kommentiert von Fulya Antakli, aus: http://www.manfred-huth.de/ Klieme, E. (2005). Bildungsqualität und Standards, in: Becker, G. BremerichVos u. a. (Hrsg.) Standards, Friedrich Jahresheft XXIII/2005, Seelze Konferenz der Kultusminister der Länder: Reihe „Bildungsstandards“, Neuwied $2004-2006$

Neuner, G. mit Kilian, V. und Schmitt, W. (Hrsg.) (1995). Deutsch als Zweitsprache in der Erwachsenenbildung: Curriculumentwicklung Übungsmaterial - Lehrerfortbildung. München 1995

Okay, Erman (1991). Keloglan und der Riese. Türkische und deutsche Märchen. Eine Tonkassette für Kinder. Mit Begleitheft. Weinheim und Basel: Beltz Verlag

PRESSE- UND INFORMATIONSAMT DER BUNDESREGIERUNG (2008). PRESSEMITTEILUNG NR.:159. Jugendintegrationsgipfel fordert mehr Chancengleichheit für Migranten, Mo, 05.05.2008. http://www.bundesregierung.de/Content/DE/Pressemitteilungen/BPA/2008/05/2 008-05-05-jugendintegrationsgipfel-integrationsbeauftragte.html Tischler, Lothar C. / Kisseler, Wolfgang / Trabert, Lioba (2002). FEHReport Nr.: 637, Forschungs- und Entwicklungsgesellschaft Hessen mbH (FEH), Wiesbaden, Migrationsreport Hessen 2002, S. 161 Wörner, Manfred (2003). Migration und Schulerfolg, in: Baden-Württemberg in Wort und Zahl, Heft1/2003, S. 36-42 